



\title{
A Comprehensive Technical Package for the Prevention of Youth Violence and Associated Risk Behaviors
}

\author{
Prepared by: \\ Corinne David-Ferdon, PhD \\ Alana M. Vivolo-Kantor, PhD, MPH \\ Linda L. Dahlberg, PhD \\ Khiya J. Marshall, DrPH, MPH \\ Neil Rainford, MHSE \\ Jeffery E. Hall, PhD
}

2016

Division of Violence Prevention

National Center for Injury Prevention and Control

Centers for Disease Control and Prevention

Atlanta, Georgia 
A Comprehensive Technical Package for the Prevention of Youth Violence and Associated Risk Behaviors is a publication of the National Center for Injury Prevention and Control of the Centers for Disease Control and Prevention.

\title{
Centers for Disease Control and Prevention
}

Thomas R. Frieden, MD, MPH, Director

\section{National Center for Injury Prevention and Control \\ Debra E. Houry, MD, MPH, Director}

\author{
Division of Violence Prevention \\ James A. Mercy, PhD, Director
}

\section{Suggested citation:}

David-Ferdon, C., Vivolo-Kantor, A. M., Dahlberg, L. L., Marshall, K. J., Rainford, N. \& Hall, J. E. (2016). A Comprehensive Technical Package for the Prevention of Youth Violence and Associated Risk Behaviors. Atlanta, GA: National Center for Injury Prevention and Control, Centers for Disease Control and Prevention. 


\section{Contents}

Acknowledgements

5

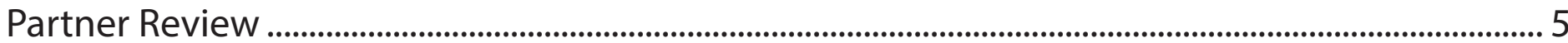

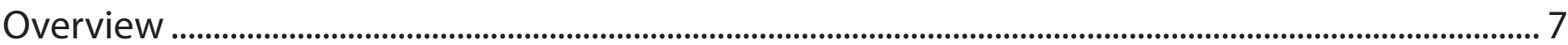

Promote Family Environments that Support Healthy Development .................................................... 15

Provide Quality Education Early in Life....................................................................................................... 18

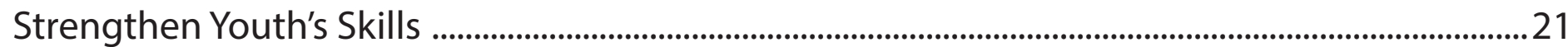

Connect Youth to Caring Adults and Activities .........................................................................................25

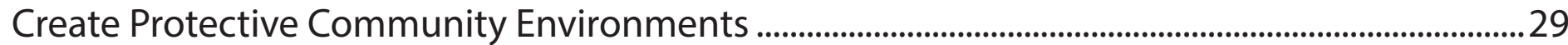

Intervene to Lessen Harms and Prevent Future Risk ............................................................................33

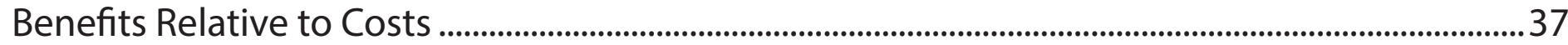

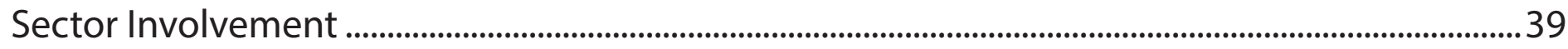

Monitoring and Evaluation ............................................................................................................................... 41

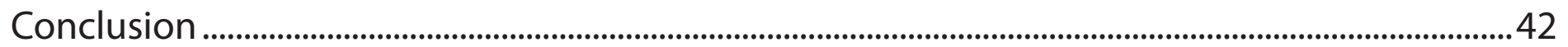

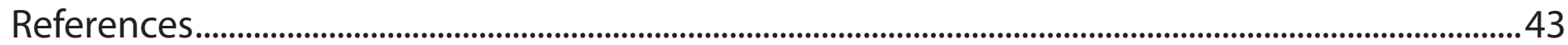

Appendix: Summary of Strategies and Approaches to Prevent Youth Violence .............................60 


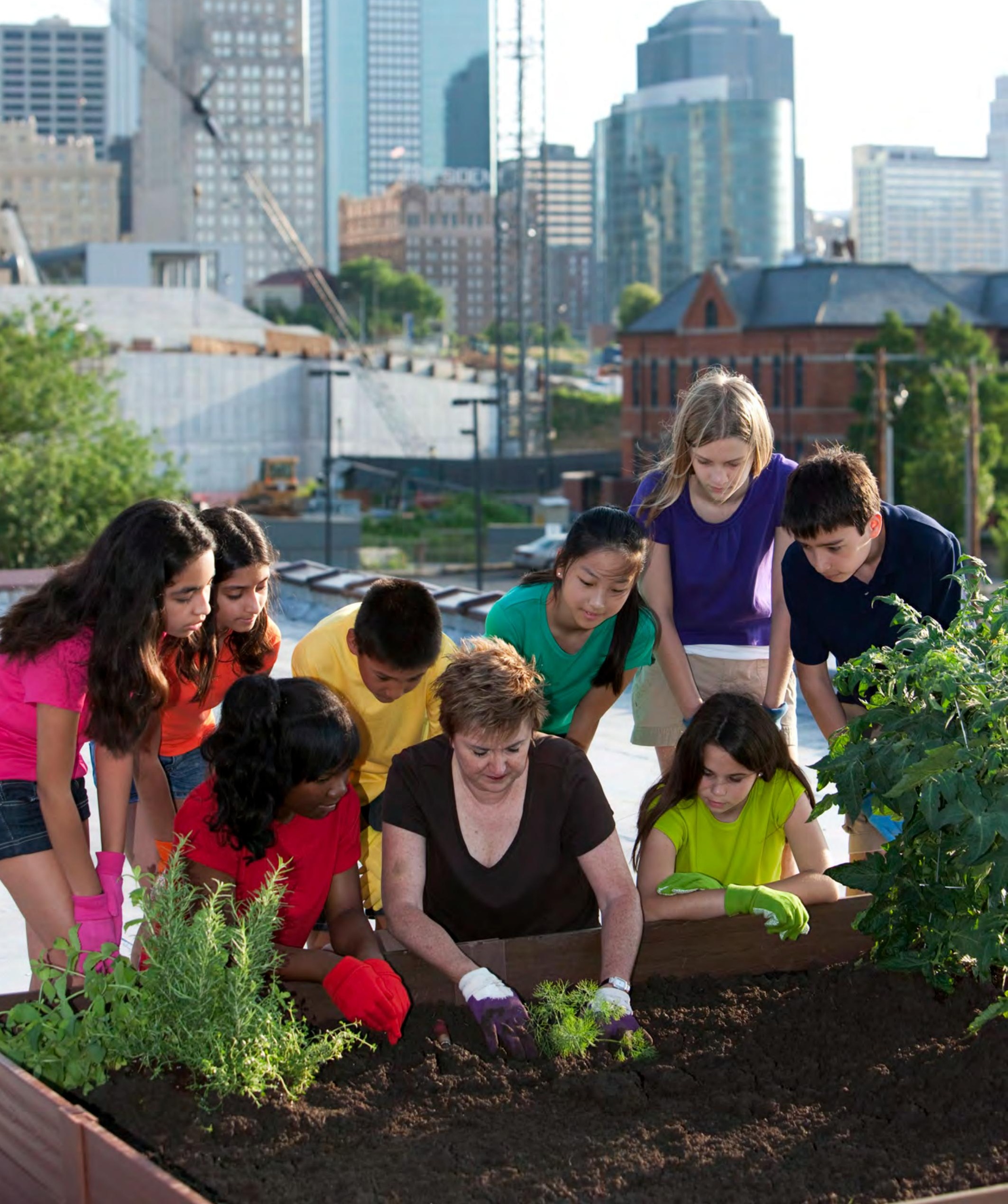




\section{Acknowledgements}

This technical package is based on decades of youth violence prevention research, and we are appreciative of the hard work of the many individuals who have developed a tremendous amount of knowledge that makes the prevention of youth violence possible. We thank Division, Center, CDC leadership and other CDC prevention scientists, including Sarah Bacon, Kevin Vagi, and Brad Bartholow, for their input, careful review, and helpful feedback on earlier iterations of this resource. We thank Alida Knuth for her formatting and design expertise.

We also extend our gratitude to all of our partners for their helpful feedback, support, and encouragement for this resource. We would like to especially thank the American Institutes for Research, American Psychological Association, Equal Justice USA, Michigan Youth Violence Prevention Center, Monterey County Health Department, National League of Cities, North Carolina Rural Academic Center of Excellence in Youth Violence Prevention, Prevention Institute, Safe States Alliance, and our Federal colleagues in the National Institute for Occupational Safety and Health and in the Office of Minority Health for their helpful written feedback on this package.

\section{Partner Review}

CDC provided an overview of the youth violence technical package to partners and grantees in a series of webinars. A draft of the youth violence technical package was also shared with partners and grantees following the webinars. These partner organizations are listed below.

\section{Striving To Reduce Youth Violence Everywhere (STRYVE) Action Council}

American Academy of Pediatrics

American Association of School Administrators

American Psychological Association

American Public Health Association

Association of State and Territorial Health Officials

Boys and Girls Clubs of America

Community Anti-Drug Coalitions of America

Hope Matters International

Illinois Children's Mental Health Partnership

Local Initiatives Support Corporation

National Association of County and City Health Officials

National Association of Students Against Violence Everywhere

National Council of Juvenile and Family Court Judges

National League of Cities

Prevention Institute

Safe States Alliance

Young Men's Christian Association

\section{STRYVE Technical Assistance and Grantees}

American Institutes for Research

Boston Public Health Commission (MA)

Houston Health Department (TX)

Monterey County Health Department (CA)

Multnomah County Health Department (OR)

\author{
National Centers of Excellence in Youth Violence Prevention \\ Chicago Center for Youth Violence Prevention \\ Clark-Hill Institute for Positive Youth Development \\ Denver National Center of Excellence in Youth Violence \\ Prevention \\ Johns Hopkins Center for the Prevention of Youth Violence \\ Michigan Youth Violence Prevention Center \\ North Carolina Rural Academic Center of Excellence in Youth \\ Violence Prevention \\ University of Louisville Youth Violence Prevention Center
}

CDC's Division of Violence Prevention Policy Network

American Academy of Pediatrics

American College of Preventive Medicine

American Foundation for Suicide Prevention

American Psychological Association

California Coalition Against Sexual Assault

Futures Without Violence

National Association of County and City Health Officials

National Resource Center on Domestic Violence

National Sexual Violence Resource Center

North Carolina Coalition Against Sexual Assault

Prevent Child Abuse America

Prevention Institute

Safe States Alliance

\section{Federal Partners}

United States Department of Justice

Office of Minority Health

National Institute for Occupational Safety and Health 


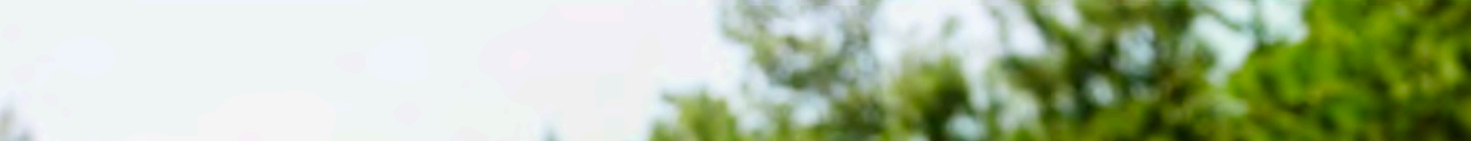

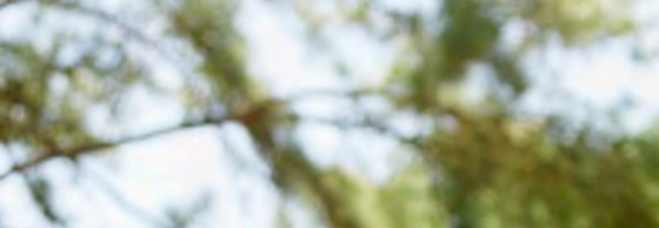

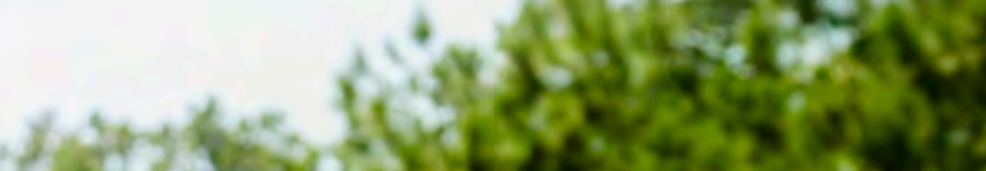

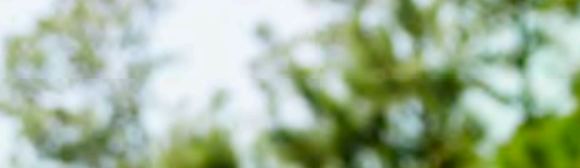

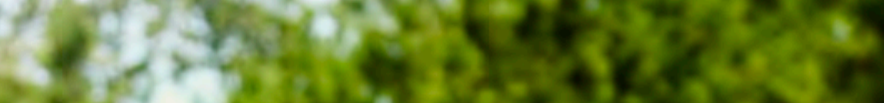
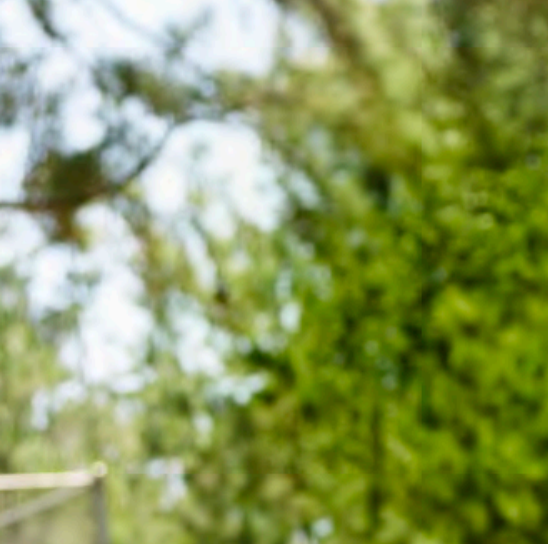


\section{Overview}

This technical package represents a select group of strategies based on the best available evidence to help communities and states sharpen their focus on prevention activities with the greatest potential to prevent youth violence and its consequences. These strategies include promoting family environments that support healthy development; providing quality education early in life; strengthening youth's skills; connecting youth to caring adults and activities; creating protective community environments; and intervening to lessen harms and prevent future risk. The strategies represented in this package include those with a focus on preventing youth violence from happening in the first place as well as approaches to reduce the immediate and long-term harms of youth violence in order to prevent future violence. Preventing youth violence requires multiple, complementary strategies, and those outlined in the package reflect the mature research-base about how to strengthen individual's skills and relationships to prevent youth violence. ${ }^{1,2}$ It also includes promising evidence about ways to address broader community issues that affect the likelihood of youth violence.

This package supports CDC's STRYVE initiative for preventing youth violence. In particular, this package articulates a select set of strategies and specific approaches to achieve STRYVE's vision of safe and healthy youth achieving their full potential (see box to the right). Commitment, cooperation, and leadership from numerous sectors, including public health, education, justice, health care, social services, business, and government, can bring about the successful implementation and long-term impact of this package.

\section{What is a Technical Package?}

A technical package is a compilation of a core set of strategies to achieve and sustain substantial reductions in a specific risk factor or outcome. ${ }^{3}$ Technical packages help communities and states prioritize prevention activities based on the best available evidence. This technical package has three components. The first component is the strategy or the preventive direction or actions to achieve the goal of preventing youth violence. The second component is the approach. The approach includes the specific ways to advance the strategy. This can be accomplished through programs, policies, and practices. The evidence for each of the approaches in preventing youth violence or its associated risk factors is included as the third component. This package is intended as a resource to guide and inform prevention decision-making in communities and states.

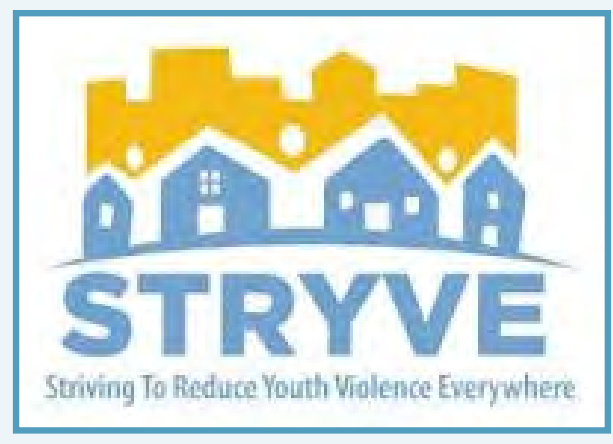

\section{CDC's Striving To Reduce Youth Violence Everywhere Initiative}

STRYVE's vision is safe and healthy youth who can achieve their full potential as connected and contributing members of thriving violence-free families, schools, and communities. STRYVE works to:

- Increase public health leadership to prevent youth violence

- Promote the widespread use of youth violence prevention strategies based on the best available evidence

- Achieve national reductions in youth violence

STRYVE has several interacting components that all contribute to the achievement of the vision, including national partnerships, online training and tools, and technical assistance.

http://www.cdc.gov/ violenceprevention/stryve/index.html 
$\infty$

\section{Preventing Youth Violence is a Priority}

Youth violence is a significant public health problem that affects thousands of young people each day, and in turn, their families, schools, and communities. Youth violence occurs when young people between the ages of 10 and 24 years intentionally use physical force or power to threaten or harm others. ${ }^{1,4}$ Youth violence typically involves young people hurting other peers who are unrelated to them and who they may or may not know well. Youth violence can take different forms. Examples include fights, bullying, threats with weapons, and gang-related violence. A young person can be involved with youth violence as a victim, offender, or witness. Different forms of youth violence can also vary in the harm that results and can include physical harm, such as injuries or death, as well as psychological harm, increased medical and justice costs, decreased property values, and disruption of community services. ${ }^{5}$

Youth violence is highly prevalent. Youth violence is a leading cause of death and nonfatal injuries in the United States. Homicide is the third leading cause of death among persons aged 10 to 24 years. ${ }^{6}$ The majority of these homicides are from firearm violence. In $2014,86 \%$ of youth homicide victims were killed with a firearm. ${ }^{6}$ The number of young persons who are treated for nonfatal physical assault-related injuries in emergency departments in the United States is more than 115 times higher than the number killed. ${ }^{6}$ Each day approximately 12 young people are victims of homicide and an additional 1,374 are treated in emergency departments for nonfatal physical assaultrelated injuries. ${ }^{6}$ Additionally, self-report information indicates that 1 in 5 high school students was bullied at school or in a physical fight in the past year. ${ }^{7}$ Although the rates of youth homicide and crime are declining, these promising trends are inconsistent across population groups and the public health burden remains too high. For instance, the decline in homicide rates among non-Hispanic Black youth is less than the decline for non-Hispanic White youth. ${ }^{8}$ Homicide has been the leading cause of death for non-Hispanic Black youth for more than three decades and is the second leading cause of death for Hispanic youth. ${ }^{6}$

Youth violence is a significant problem that negatively impacts youth in urban, suburban, rural, and tribal communities. The rates and forms of youth violence, however, vary across subgroups of youth and communities. Relative to females and non-Hispanic White youth, young males and racial/ethnic minorities experience the greatest burden of youth violence with higher prevalence of homicide, physical injuries, and fighting. ${ }^{6,7}$ Females and sexual minority youth have higher prevalence of in-person and electronic bullying than males and heterosexual peers. ${ }^{7}$ Youth gang activity and violent crime are higher in larger cities than suburban and rural communities., ${ }^{9,10}$

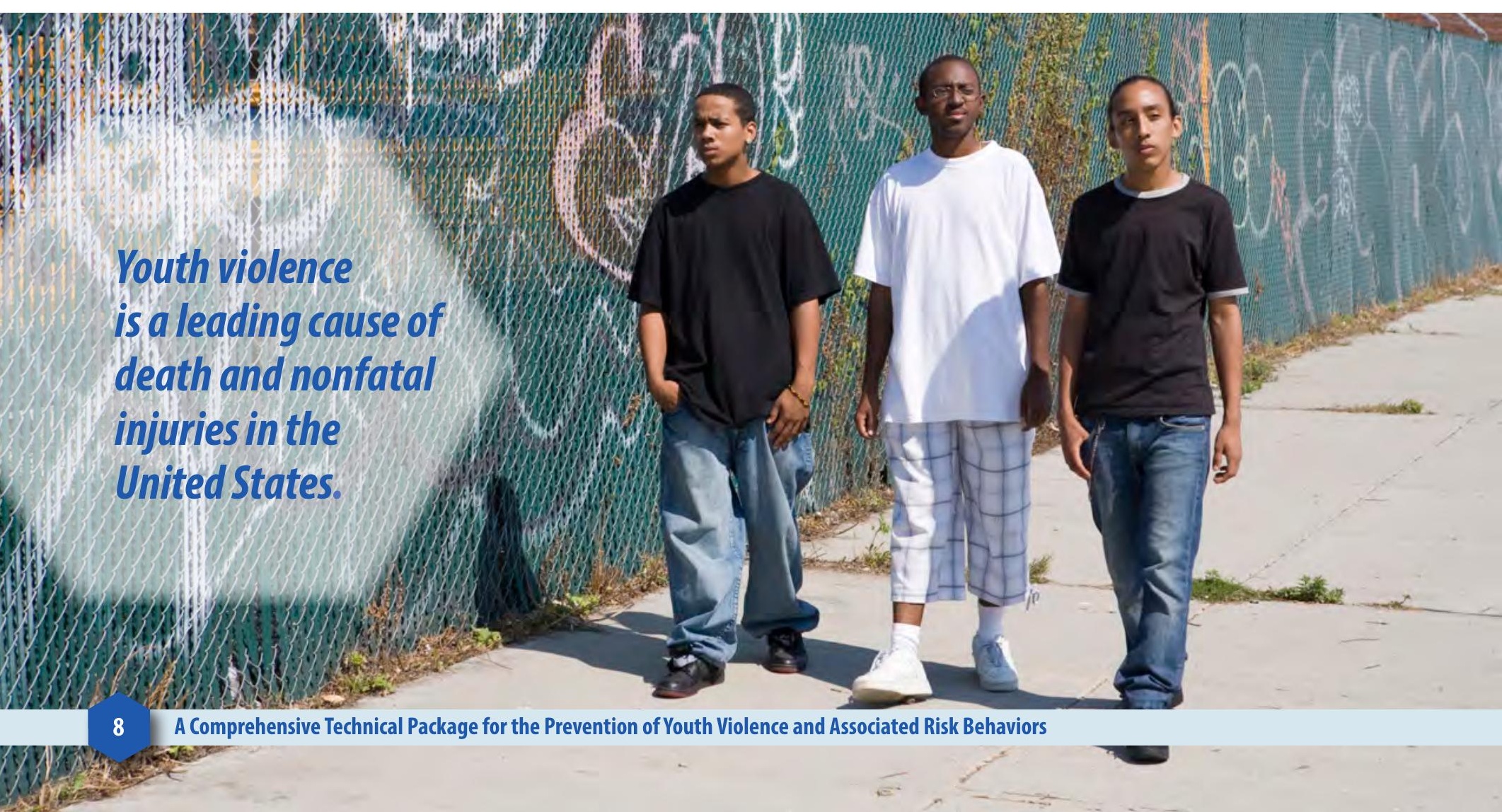


The health and economic consequences of youth violence are substantial. Youth violence has serious and lasting effects on the physical, mental, and social health of young people. It is a leading cause of death for young people and results in more than 500,000 medically treated physical injuries each year. ${ }^{6}$ The impact of youth violence extends well beyond physical consequences. Youth who experience violence as victims, perpetrators, or witnesses are more likely to have behavioral and mental health difficulties, including future violence perpetration and victimization, smoking, substance use, obesity, high-risk sexual behavior, depression, academic difficulties, school dropout, and suicide. ${ }^{11-15}$

An entire community feels the burden of youth violence. For instance, youth homicides and nonfatal physical assault-related injuries result in an estimated $\$ 18.2$ billion annually in combined medical and lost productivity costs alone. ${ }^{6}$ This estimate is a fraction of the true economic consequences of youth violence because it does not include criminal justice system costs, such as arrest, prosecution, incarceration, and re-entry, or the costs associated with addressing the psychological and social consequences for victims, perpetrators, and their families. It also does not include the costs incurred by communities to address victims' needs (e.g., property damage, lost wages, physical and mental health care) that result from youth violence and crime or the substantial economic impacts on communities' healthcare system, property values, and social services systems. ${ }^{5,16,17}$ The costs of responding to youth violence significantly limit the resources states and communities have to address other needs and goals.

Youth violence starts early in the lifespan. Physical aggression can be common among toddlers, and most children learn alternatives to using violence to solve problems and express their beliefs and emotions before starting elementary school. ${ }^{18} \mathrm{~A}$ subset of children, however, continue to be aggressive, and if their problematic behaviors are not addressed their aggression can persist and increase. ${ }^{2}$ In addition to early physical aggression, many other factors associated with the future perpetration of violence, such as impulsivity, poor emotional control, and weak social and problem-solving skills, are evident in early childhood. ${ }^{19-21}$ Many risks for violence, such as child abuse and neglect, academic problems, and poor supervision and management of children's behavior, also emerge early and heighten the likelihood for violence during adolescence and young adulthood. These signs provide opportunities to change behaviors and conditions before violence patterns are established and become harder to modify. ${ }^{18}$

Youth violence is associated with several risk and protective factors. Youth violence is influenced by the interaction of multiple factors, including a young person's characteristics and experiences as well as by the relationships, community, and society within which young people develop. No one factor, in isolation, leads to the development of youth violence, and the presence of risks does not always mean a young person will experience violence. Individual and interpersonal risks for perpetrating violence include impulsiveness, youth substance use, antisocial or aggressive beliefs and attitudes, low levels of school achievement, weak connection to school, experiencing child abuse and neglect, exposure to violence in the home or community, involvement with delinquent peers or gangs, lack of appropriate supervision, parental substance abuse, and parental or caregiver use of harsh or inconsistent discipline. 1,25,21,22 Depression, anxiety, chronic stress and trauma, and peer conflict and rejection are also associated with youth violence perpetration and victimization.,23-27 Youth who are arrested, particularly before age 13, have a heighten risk for future violence and crime, school dropout, and substance abuse. ${ }^{18,20,28-30}$ In addition, unsupervised access to a firearm is a contributing factor for lethal youth violence. ${ }^{31,32}$ An increased risk for youth violence and crime is associated with many community factors, such as residential instability, crowded housing, density of alcohol-related businesses, poor economic growth or stability, unemployment, concentrated poverty, neighborhood violence and crime, lack of positive relationships among residents, and views that drug use and violence are acceptable behaviors. ${ }^{33-37}$ Some racial/ethnic minority youth are exposed to high levels of community violence and other neighborhood problems, which contribute to disparities in youth violence, violence-related injuries and death, and other difficulties..$^{38-40}$

Evidence is mounting that many factors can buffer or reduce the likelihood of youth violence, and multiple protective factors can even offset the potential harmful influence of risk factors that have accumulated over a child's development. ${ }^{41-43}$ Protective factors include healthy social, problem-solving, and emotional regulation skills and a young person's school readiness and academic achievement. ${ }^{41,43-45}$ Positive and warm parent-youth relationships in which parents set consistent, developmentally appropriate limits and demonstrate interest in their children's education and social relationships are associated with healthy child and adolescent development and the prevention of violent behavior. ${ }^{33,44,46-52}$ Additional factors that contribute to healthy adolescent development and decrease 


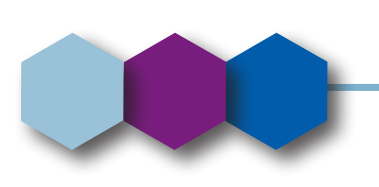

aggressive behavior include youth feeling connected to their schools, experiencing academic success, having positive relationships with teachers and other caring adults, and interacting with prosocial and nonviolent peers. 18,44,53-55

Physical environments of schools, parks, and business and residential areas that are regularly repaired and maintained and designed to increase visibility, control access, and promote positive interactions and appropriate use of public spaces also are buffers to violence. ${ }^{56-58}$ Additional community buffers against violence and associated risks include household financial security, safe and stable housing, economic opportunities, increasing access to services and social support, residents willingness to assist each other, and collective views that violence is not acceptable. ${ }^{59-63}$

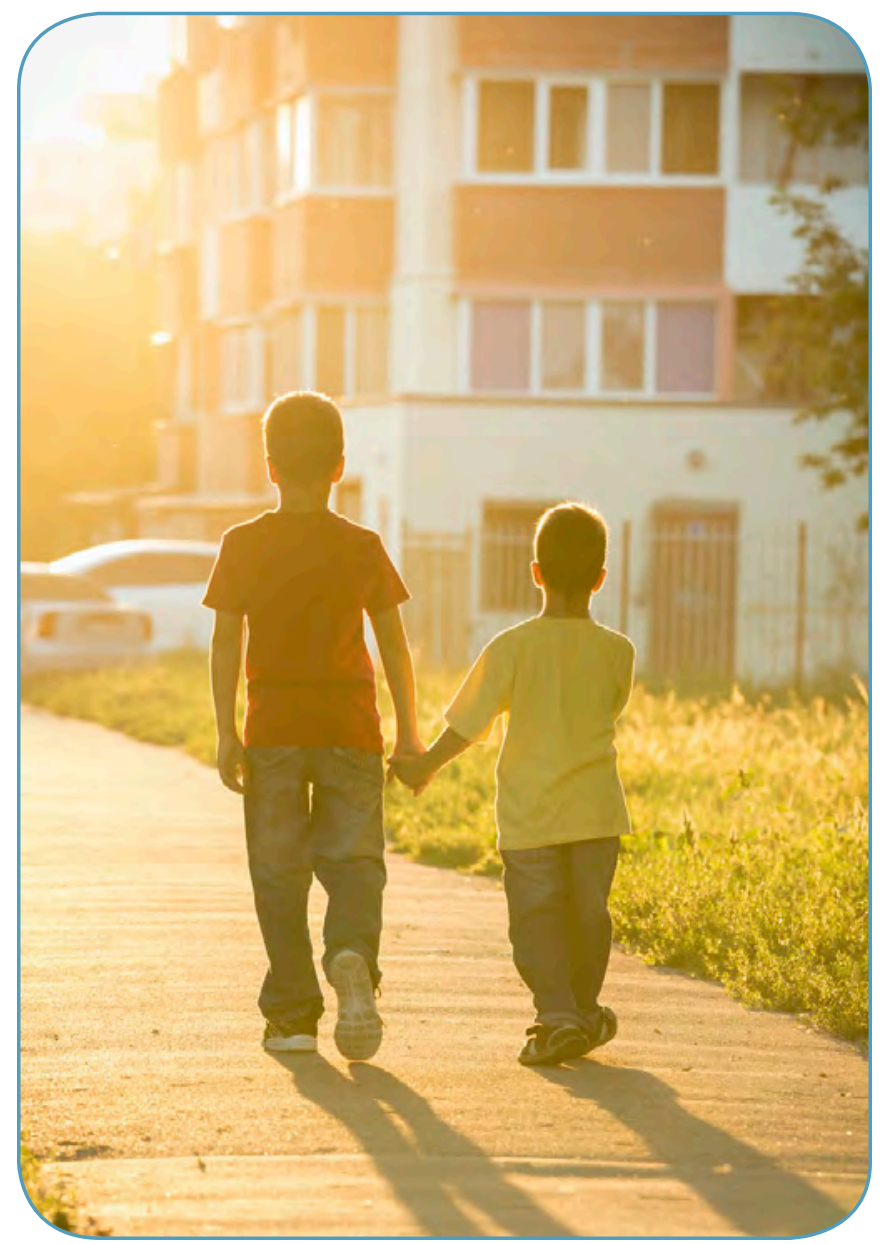

Youth violence is connected to other forms of violence. The different forms of violence, including youth violence, child abuse and neglect, teen dating violence, adult intimate partner violence, sexual violence, and suicide, have many common risk and protective factors. ${ }^{64,65}$ Many of these risks are the result of exposure to chronic stress that can alter and harm prenatal and child and adolescent brain development and, in turn, negatively impact attention, impulsivity, decision-making, learning, emotional control, and response to stress. ${ }^{64,66-68}$ Chronic stress includes such issues as living in impoverished neighborhoods, living in dilapidated housing, frequently moving, experiencing food insecurity, experiencing racism, limited access to support and medical services, and living in homes with violence, mental health problems, substance abuse, and other instability. Some forms of violence can increase the risk for other forms of violence. For example, individuals who experience child abuse and neglect are significantly more likely to be in physical fights, be affiliated with a gang, damage property, and attempt suicide during adolescence and young adulthood than those who do not experience child maltreatment. ${ }^{69}$ Bullying is associated with an increased risk for weapon carrying, physical fighting, and other forms of violence, such as suicide, teen dating violence, and subsequent sexual harassment perpetration. ${ }^{70-74}$ Approaches that address risk and protective factors that are common across multiple forms of violence may be an effective and efficient way to prevent violence. $^{64}$

Youth violence can be prevented. A strong and growing research base demonstrates that there are multiple prevention strategies that are scientifically proven to reduce youth violence victimization and perpetration and associated risk factors. ${ }^{1,2,21,75-77}$ As described in the Benefits Relative to Cost section of this technical package, many evidence-based youth violence prevention programs and policies have economic benefits, with community savings far outweighing implementation costs..$^{78-80}$ Strategies are available that benefit all youth regardless of their level of risk as well as individuals and environments at greatest risk. Because youth violence results from multiple individual, family, and environmental factors that can accumulate over a child's development, the use of one strategy will have limited effects on an entire community's level of violence and its ability to sustain initial program benefits. A comprehensive approach that simultaneously targets multiple risk and protective factors is critical to having a broad and continued impact on youth violence. ${ }^{1,22,81-83}$ Stopping youth violence before it occurs and sustaining this proactive approach throughout childhood and adolescence can be done with available programs, practices, and policies. 


\section{Assessing the Evidence}

This technical package includes programs, practices, and policies with evidence of impact on youth violence victimization, perpetration, and risk or protective factors for youth violence. To be considered for inclusion in the technical package, the program, practice, or policy selected had to meet at least one of these criteria: a) meta-analyses or systematic reviews showing impact on youth violence victimization or perpetration; b) evidence from at least one rigorous (e.g., randomized controlled trial $[\mathrm{RCT}]$ or quasi-experimental design) evaluation study that found significant preventive effects on youth violence victimization or perpetration; c) meta-analyses or systematic reviews showing impact on risk or protective factors for youth violence victimization or perpetration; or d) evidence from at least one rigorous (e.g., RCT or quasi-experimental design) evaluation study that found significant impacts on risk or protective factors for youth violence victimization or perpetration. Finally, consideration was also given to the likelihood of achieving beneficial effects on multiple forms of violence; no evidence of harmful effects on specific outcomes or with particular subgroups; ${ }^{*}$ and feasibility of implementation in a United States (U.S.) context if the program, policy, or practice has been evaluated in another country.

The evidence base for youth violence prevention, particularly for approaches focused on building youth's skills and positive family environments and relationships, is strong as evidenced by multiple meta-analyses and systematic reviews demonstrating impact of these approaches on behavioral outcomes. In terms of the strength of the evidence, meta-analyses or systematic reviews of programs that have demonstrated effects on behavioral outcomes provide a higher level of evidence. However, the evidence base is not that strong in all areas. For instance, there has been less evaluation of the effects of programs and policies that address community issues that affect the likelihood of youth violence. Community-level approaches in this package showing impacts on risk (e.g., community crime rates, drug use) or protective factors (e.g., positive adult supervision and role models, positive school climate) reflect the developmental nature of the evidence base in this area and the use of the best available evidence at a given time.

Despite being an important contributor to lethal and nonlethal violence among youth, there is a dearth of evidence regarding effective approaches to reduce youths' unsupervised access, possession, and use of firearms. This particular gap was noted in the Institute of Medicine and the National Research Council's report Priorities for Research to Reduce the Threat of Firearm-Related Violence. ${ }^{88}$ For these reasons, strategies and approaches specific to unsupervised access, possession, and weapon use are not included, although many of the strategies and approaches that are included in the package are designed to address risk and protective factors to prevent youth from becoming involved in firearm-related violence in the first place.

In terms of the strategies and approaches in the package, it is important to note that there can be significant heterogeneity among the programs, policies, or practices that fall within one approach or strategy area in terms of the nature and quality of the available evidence. Not all programs, policies, or practices that utilize the same approach (e.g., home visitation, mentoring) are equally effective, and even those that are effective may not work across all populations. 2,8 Tailoring programs and conducting more evaluation may be necessary to better understand effectiveness across different population groups and communities. ${ }^{90}$ The examples provided in this technical package are not intended to be a comprehensive list of evidence-based programs, policies, or practices for each approach, but rather illustrate models that have been shown to impact youth violence victimization or perpetration or have beneficial effects on risk or protective factors for youth violence and could be implemented in communities.

Identifying activities with evidence of impact on victimization, perpetration, and risk or protective factors for youth violence is only the first step. In practice, the effectiveness of the programs, policies and practices identified in this package will be strongly dependent on how well programs are implemented as well as the partners and communities in which they are implemented..$^{91,92}$ The readiness of the program for broad dissemination and implementation (e.g., availability of program materials, training and technical assistance) can also influence program effects. Implementation guidance to assist practitioners, organizations and communities will be developed separately.

\footnotetext{
* Research shows some programs, practices, and policies have harmful effects on youth's behavior. ${ }^{2,29,84-87}$ Reasons for harmful effects may include lack of youth's skill development in real-world settings, limited adult supervision, and increased opportunities for delinquent youth to associate with each other. Examples of ineffective approaches include: transfer of juvenile offenders to the adult criminal system; shock and military-style programs (e.g., Scared Straight, boot camps); residential or individual treatment used in isolation; training youth to mediate peer conflict in school settings; and not promoting youth to succeeding grades.
} 


\section{Contextual and Cross-Cutting Themes}

The strategies and approaches included in this technical package represent different levels of the social ecology, with efforts intended to impact individual behaviors and also the relationships, families, schools, and communities that influence risk and protective factors for youth violence. The strategies and approaches are intended to work in combination and reinforce each other to prevent youth violence in a comprehensive and long-term way (see box below). While individual skills are important and research has demonstrated the preventive effects of many youth skill development programs, approaches addressing relationships with parents, peers, and other caring adults as well as approaches that influence school and community environments are equally important to have the greatest public health impact.

\section{Preventing Youth Violence}

\begin{tabular}{|l|l|}
\hline Strategy & Approach \\
\hline $\begin{array}{l}\text { Promote family environments that } \\
\text { support healthy development }\end{array}$ & $\begin{array}{l}\text { - Early childhood home visitation } \\
\text { - Parenting skill and family relationship programs }\end{array}$ \\
\hline Provide quality education early in life & - Preschool enrichment with family engagement \\
\hline Strengthen youth's skills & - Universal school-based programs \\
\hline $\begin{array}{l}\text { Connect youth to caring adults and } \\
\text { activities }\end{array}$ & $\begin{array}{l}\text { - Mentoring programs } \\
\text { - After-school programs }\end{array}$ \\
\hline $\begin{array}{l}\text { Create protective community } \\
\text { environments }\end{array}$ & $\begin{array}{l}\text { - Modify the physical and social environment } \\
\text { - Reduce exposure to community-level risks } \\
\text { - Street outreach and community norm change }\end{array}$ \\
\hline $\begin{array}{l}\text { Intervene to lessen harms and } \\
\text { prevent future risk }\end{array}$ & $\begin{array}{l}\text { - Treatment to lessen the harms of violence exposures } \\
\text { - Treatment to prevent problem behavior and further involvement } \\
\text { in violence } \\
\text { - Hospital-community partnerships }\end{array}$ \\
\hline
\end{tabular}

The social and cultural context of communities and organizations is critically important to take into account when selecting strategies and approaches for implementation. Practitioners in the field may be in the best position to assess the needs and strengths of their communities and work with partners to make decisions about the combination of approaches included here that are best suited to their context. Data-driven strategic prevention planning models, such as Communities That Care (CTC), PROmoting School-community-university Partnerships to Encourage Resiliency (PROSPER), and the Cardiff Violence Prevention Partnership, can support communities in using data to assess local risks and protective factors to inform the selection and ongoing monitoring of evidence-based programs. These datadriven partnerships and activities can contribute to significant reductions in violence, violence-related injuries, and crime as well as cost savings for the medical, educational, and justice systems. ${ }^{95-102}$ 


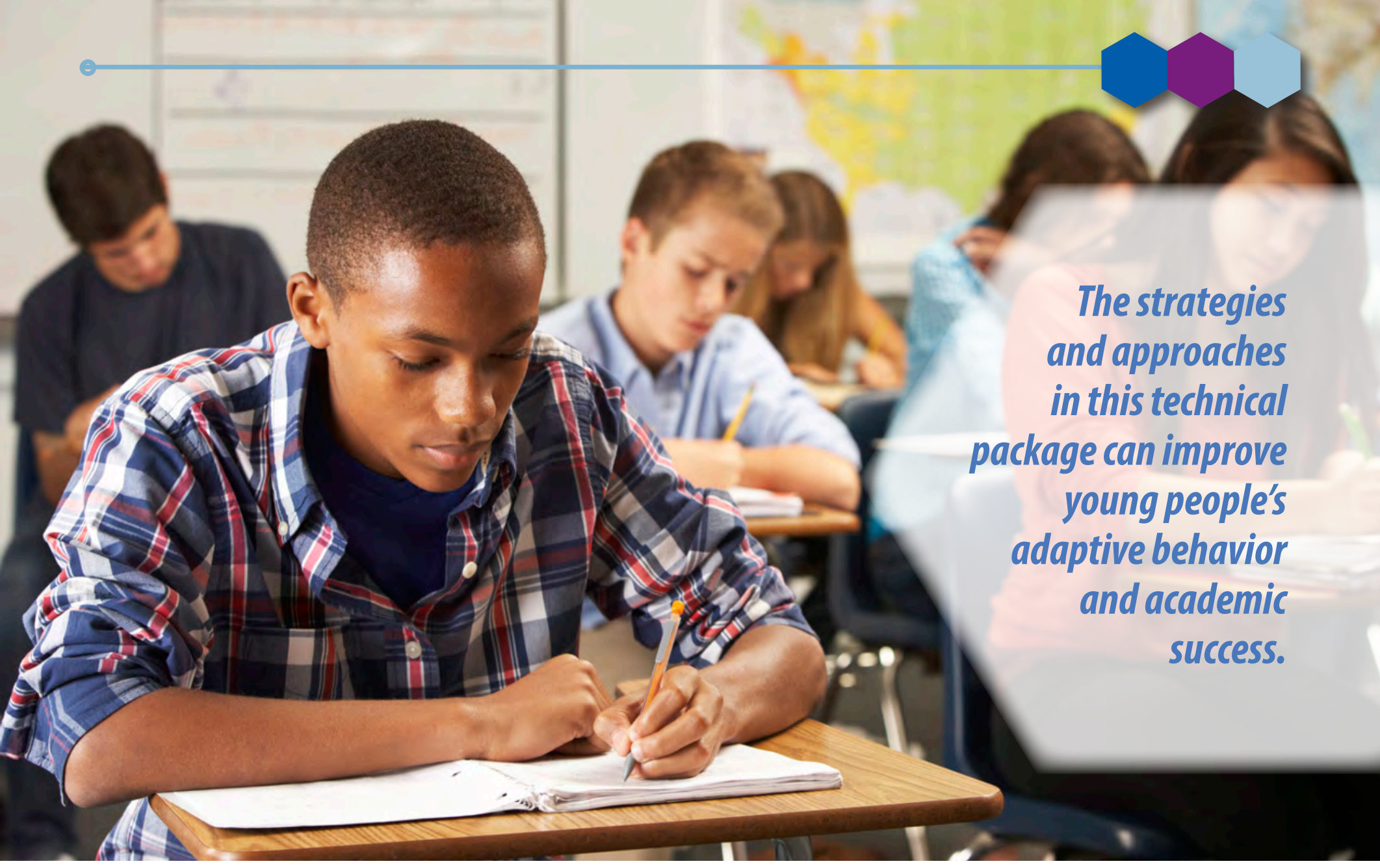

The strategies and approaches in this package have the potential to reduce multiple forms of violence (e.g., child abuse and neglect, teen dating violence, sexual violence) and other adolescent health problems (e.g., teen pregnancy, sexually transmitted infections). The strategies and approaches in this technical package can improve young people's adaptive behavior and academic success. For instance, school-based programs that strengthen youth's problemsolving and conflict management skills can reduce physical and verbal violence, bullying, teen dating violence, sexual violence, alcohol and drug use, and sexual risk behaviors. ${ }^{76}$ They can also be used to strengthen academic performance, improve graduation rates, and create a positive school climate. Given that many risks for youth violence are evident before adolescence, programs that are designed to promote healthy child development and reduce the likelihood of child abuse and neglect can also potentially prevent violence in the teen years and in adulthood..$^{103-105}$ The interconnection of these experiences and risk and protective factors suggests that the implementation of strategies and approaches to prevent youth violence can have substantial, long-term health, social, and economic benefits. ${ }^{64,65}$ However, it is also important to note that child abuse and neglect, teen dating violence, and sexual violence may also require additional prevention activities than those outlined in this technical package. CDC has developed technical packages for these other forms of violence to help communities identify additional strategies and approaches. ${ }^{106-109}$

Public health has a clear responsibility to help reduce the health burden of youth violence, has expertise applying science to reduce the risk for complex health problems, and can act to reduce youth violence. ${ }^{1}$ This package includes strategies where public health agencies are well positioned to bring leadership and resources to implementation efforts. It also includes strategies where public health can serve as an important collaborator (e.g., strategies addressing community-level risks), but where leadership and commitment from other sectors, such as business, is critical to implement a particular policy or program (e.g., business improvement districts). The role of various sectors in the implementation of a strategy or approach in preventing youth violence is described further in the section on Sector Involvement.

In the sections that follow, the strategies and approaches with the best available evidence for preventing youth violence are described. 


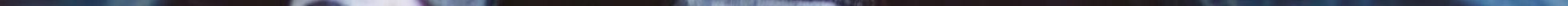




\section{Promote Family Environments that Support Healthy Development}

\section{Rationale}

The family environment plays a key role in shaping youth's physical, emotional, social, and behavioral health, and this influence extends from early childhood through late adolescence and beyond. ${ }^{110-111}$ Family environments that are unstable, stressful, lack structure and supervision, have poor relationships and communication between family members, and use harsh or limited discipline with children are risk factors for youth violence and contribute to young people developing other risks, such as poor problem-solving skills and early and continued perpetration of aggression. ${ }^{33,48,112,113}$ Decades of research show that nurturing and supportive family environments where caregivers build warm and caring relationships with children, monitor children's activities and friendships, set age-appropriate expectations and rules, and use consistent and nonviolent discipline significantly lower the risk for youth violence and other adolescent health risk behaviors. ${ }^{33,46-52}$ The promotion of positive family environments throughout a child's development is connected to caregivers' knowledge about healthy and age-appropriate child development as well as the ways families communicate, manage behavior, and resolve conflict.

\section{Approaches}

There are a number of approaches that can help families create and maintain supportive, nurturing, and structured environments at every stage of a young person's development.

Early childhood home visitation programs provide information, caregiver support, and training about child health, development, and care to families in their homes, and help families access services. Home visiting programs may be delivered by nurses, professionals, or paraprofessionals. ${ }^{14}$ Many programs are offered to low-income, first time mothers to help them establish healthy family environments. ${ }^{114}$ The content and structure of programs can also vary depending on the model being utilized, with some being highly manualized and others being more flexible in delivery. ${ }^{114}$ Some programs begin during pregnancy, while others begin after the birth of the child and may continue up through the child entering elementary school.

Parenting skill and family relationship programs provide caregivers with support and teach communication, problem-solving, and behavior monitoring and management skills. These programs can be self-directed or delivered to individual families or groups of families. For families at high risk for conflict and child behavior problems, tailored delivery to individual families yields greater benefits than group administration. ${ }^{47,115,116}$ Single-parent families often participate in these programs, and some programs have sessions primarily with parents while others include parent, youth, and family sessions. Programs are typically designed for families with children in a specific age range, with some designed for preschool and elementary aged children and others for middle and high-school aged youth. ${ }^{49,115}$ Specific program content typically varies by the age of the child but often has consistent themes of child development, parental monitoring and management of children's behavior, appropriate use of rewards and punishment, parent-child communication and relationships, and youth's interpersonal and problem-solving skills. ${ }^{49,51,52,115}$ 
- Reductions in behavior problems and disruptive behavior at home and school

- Reductions in physical fighting, aggression, and delinquency

- Reductions in arrests, convictions, and probation violations

- Reductions in alcohol and drug use by youth and parents

- Reductions in family conflict

- Reductions in child abuse and neglect

- Reductions in parental depression and stress

- Increases in compliance to caregiver's directions

- Increases in prosocial behavior (e.g., social skills, such as concern for others, empathy, and cooperation)

- Increases in parent-child connection, communication, and relationship quality

- Increases in positive parenting practices, such as monitoring and supervision of youth's activities, use of consistent and nonviolent discipline, and involvement and support of youth

\section{Evidence}

Approaches that enhance family environments have demonstrated effects in preventing youth violence and other adolescent health risk behaviors. ${ }^{46-52,104}$

Early child hood home visitation. Home visiting programs are effective in improving parenting behaviors and children's social and emotional development, but the evidence is mixed with some programs showing strong effects and others showing few to no effects potentially due to the varying content and delivery of these programs. ${ }^{114,117}$ Families participating in the Nurse Family Partnership ${ }^{\circledast}$ (NFP) program had 45\% fewer childhood behavior problems and parental coping problems as recorded by physicians relative to nonparticipating families, and participating youth by age 15 had significantly fewer arrests, convictions, and probation violations. ${ }^{104,118}$ Female youth at age 19 whose family participated in NFP were significantly less likely than a comparison group to be arrested (10\% versus $30 \%)$ and convicted (4\% versus 20\%)..$^{103}$ NFP also demonstrated significant impacts on risk and protective factors for youth violence, including reducing child abuse and neglect and substance use by parents and youths. ${ }^{104,119}$ The Home Visiting Evidence of Effectiveness Review identifies other home visiting programs that may work for communities, depending on available resources and the context in which the home visiting program is delivered. ${ }^{114}$

Parenting skill and family relationship programs. Multiple systematic reviews of various parent skill and family relationship approaches have demonstrated beneficial impacts on perpetration as well as risk and protective factors for youth violence. ${ }^{33,47,49,51,52,76}$ One example is The Incredible Years ${ }^{\circledR}$, which is designed for families with young children up to 12 years of age and can be implemented with additional components for teachers and children in school. A meta-analysis of effects associated with The Incredible Years ${ }^{\circledR}$ found significant decreases in children's disruptive behaviors at home and school and increases in their prosocial behaviors. ${ }^{120}$ Impacts on other risk and protective factors include reductions in parental depression and stress, improvements in children's compliance with parental directions, stronger parent-child connections and communication, and improvements in positive parenting practices related to monitoring, discipline, and mother-child interactions. ${ }^{76,121}$ Behavioral benefits are broader and sustained longer when both the parent and child participate in the program. ${ }^{121}$ Parent Management Training-Oregon Model ${ }^{\mathrm{TM}}$ (PMTO) is another example where participating youth, relative to controls, have demonstrated significantly lower rates of behavior problems, aggression, and arrest. ${ }^{122,123}$ Other program benefits of PMTO include increases in positive parenting practices and the family's socioeconomic status. ${ }^{124,125}$ 


\section{$\infty$}

\section{Provide Quality Education Early in Life}

\section{Rationale}

Quality early childhood education can improve children's cognitive and socioemotional development and increase the likelihood that children will experience safe, stable, nurturing relationships and environments and long-term academic success and health, including lower rates of behavior problems, aggression, and crime. ${ }^{136,137}$ High-quality early education environments, such as ones that are licensed and accredited, promote youth's social skill and cognitive development, strengthen connections to school, and reduce problem behaviors at school and at home. ${ }^{138,139}$ These benefits in turn contribute to stronger scholastic achievement and less family stress and conflict throughout childhood and adolescence. Early childhood education that includes parental engagement can strengthen youth outcomes, family involvement in children's future education, and parenting practices and attitudes. ${ }^{137,140,141}$ These integrated approaches also create pathways for youth and families to access ancillary supports, such as employment, transportation and meal assistance, and mental and physical health services, which can further address risks and build buffers against future violence.

\section{Approaches}

Preschool enrichment with family engagement is an approach for enhancing the foundation for a child's academic, social, and behavioral development through adolescence and into adulthood.

Preschool enrichment with family engagement programs provide high-quality early education and support to economically disadvantaged families to build a strong foundation for the children's future learning and healthy development and lower risks for future academic and behavioral problems. Programs are generally available to children and families who meet basic qualifications, such as being residents in a high-poverty school area eligible for federal Title I funding, demonstrate need and agree to participate, or have incomes at or below the federal poverty level. ${ }^{142}$ Program content and delivery vary based on the model used and can include home visits, connections to community supports, and half- to full-day child care and school programs. Parental involvement is emphasized as critical in the child's development and in increasing children's success in school. Programs often begin in infancy or toddlerhood and may continue into early or middle childhood.

\section{Potential Outcomes}

- Reductions in aggressive behavior

- Reductions in arrests, convictions, and incarceration

- Reductions in child abuse and neglect, welfare encounters, and out-of-home placements

- Reductions in grade retention and special education services

- Reductions in smoking, alcohol, and drug use

- Reductions in parent's use of harsh verbal and physical discipline

- Increases in cognitive and language development

- Increases in nurturing and supportive parent-child interactions, effective child behavior management strategies, and home environments supportive of learning

- Increases in high school completion, college attendance, and number of years of education

- Increases in full-time employment and health insurance in adulthood 


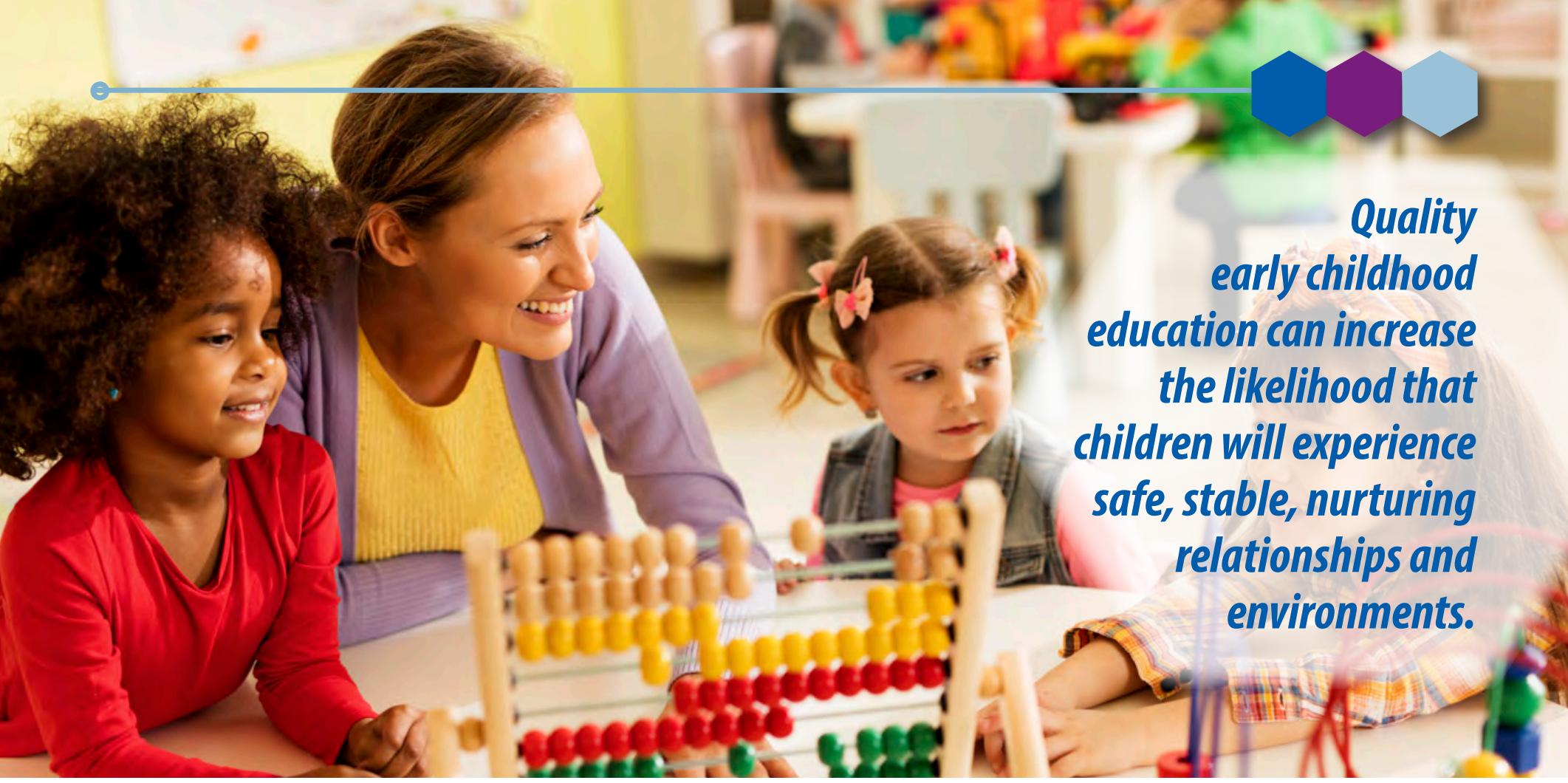

\section{Evidence}

Evidence exists that preschool enrichment programs with family engagement can reduce children's aggression and conduct problems as well as reduce youth's perpetration of violence and aggression during adolescence and young adulthood, with benefits stronger and more stable when preschool and family supports extend into early elementary school. ${ }^{143}$

Preschool enrichment with family engagement programs can lower the prevalence of problems in early childhood, including aggression and child abuse and neglect, and have broader and long-term impacts on parent-child interactions and youth's academic achievement, substance use, and perpetration of violence and crime. Examples of effective programs are Child Parent Centers (CPCS) and Early Head Start (EHS). CPCs have been evaluated in multiple, long-term studies. For instance, when followed to age 20, low-income minority children who participated in the CPC preschool program, relative to youth in other early childhood programs, had significantly lower rates of juvenile arrest (16.9\% versus $25.1 \%$ ), violent arrests (9.0\% versus $15.3 \%)$, and multiple arrests (9.5\% versus $12.8 \%) .{ }^{105}$ At age 24 , relative to youth with fewer years of CPC participation (e.g., preschool only), youth who participated in the program for 4 to 6 years had a $22 \%$ reduction in arrests for violence as well as significantly lower rates for violent convictions and multiple incarcerations. ${ }^{143}$ Across studies, youth participating in CPCs also experience numerous other benefits relative to comparison groups, including lower rates of substantiated reports of child abuse and neglect, out-of-home placements, grade retention, special education services, depression, and substance use as well as higher rates of high school completion, attendance in four-year colleges, health insurance, and full-time employment in adulthood. ${ }^{79,105,141,143}$

Multiple evaluations of EHS demonstrate significant program impacts on violence as well as other short- and longterm benefits. For instance, relative to families accessing community services, the 3-year-old children of families participating in EHS demonstrated significantly less aggressive behavior, had better cognitive and language development, and had parents who were more emotionally supportive, provided more language and learning stimulation, read to their children more often, and spanked less. ${ }^{144}$ Children in EHS also had significantly fewer child welfare encounters and substantiated reports of physical or sexual abuse encounters between the ages of 5 and 9 than did children in the control group, and EHS slowed the rate of subsequent child welfare encounters. ${ }^{145} \mathrm{Children}$ in EHS were more likely to have a substantiated report of neglect which is likely not due to EHS. Rather, enrollment in EHS may have increased monitoring of families and the visibility of young children experiencing neglect. ${ }^{145}$ The EHS homebased program when fully implemented also showed participating families had many benefits two years after the program relative to a comparison group, including children with fewer social behavior problems, stronger parent-child engagement, and home environments more supportive of learning. ${ }^{146}$ 


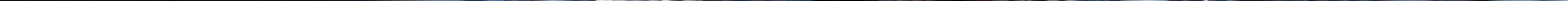




\section{Strengthen Youth's Skills}

\section{Rationale}

Strengthening youth's skills is an important component of a comprehensive approach to preventing youth violence. The likelihood of violence increases when youth have under-developed or ineffective skills in the areas of communication, problem-solving, conflict resolution and management, empathy, impulse control, and emotional regulation and management. ${ }^{2,33,147-149}$ Skill-development has an extensive and robust research base, which shows building youth's interpersonal, emotional, and behavioral skills can help reduce both youth violence perpetration and victimization. 2,21,76,77,150-152 Enhancing these skills can also impact risk or protective factors for youth violence, such as substance use and academic success. ${ }^{150,152,153}$ These life skills can help youth increase their self-awareness, accuracy in understanding social situations, ability to avoid risky situations and behaviors, and capacity to resolve conflict without violence.

\section{Approaches}

Universal school-based programs are a widely used approach to help youth develop skills to prevent violence and engage in healthy behaviors.

Universal school-based programs (sometimes also referred to as social-emotional learning approaches) work in childhood and adolescence to enhance interpersonal and emotional skills, including communication and problemsolving, empathy, emotional awareness and regulation, conflict management, and team work. ${ }^{150,151}$ This approach also provides information about violence, seeks to change the way youth think and feel about violence, and provides opportunities to practice and reinforce skills. The content and format of skill development programs vary depending on the model being utilized. These school-based approaches often include guidance to teachers and other school personnel on ways to build youth's skills, monitor and manage behavior, and build a positive school climate to reduce aggression and violence, such as bullying, and support academic success. These approaches are typically delivered to all students in a particular grade or school. These approaches can be used in all grade levels but are primarily used in elementary and middle schools. ${ }^{98}$

\section{Potential Outcomes}

- Reductions in perpetration and victimization of verbal and physical aggression

- Reductions in bullying and conduct problems

- Reductions in delinquency

- Reductions in the involvement in violent and nonviolent crime in young adulthood

- Reductions in smoking, alcohol, and drug use

- Reductions in depression and suicidal ideation

- Reductions in other adolescent risk behaviors (e.g., sex without a condom, multiple sex partners, risky driving)

- Increases in emotional regulation, understanding social situations, and developing effective and nonviolent solutions

- Increases in academic proficiency

- Increases in positive bystander behavior

- Increases in anti-bullying school policies

- Increases in positive school climate 


\section{$\infty$}

The evidence suggests that universal school-based programs can reduce aggressive behavior, including bullying, and other risky behaviors associated with youth violence.

Universal school-based programs. Multiple systematic reviews of various universal school-based programs demonstrate beneficial impacts on youth's skills and behaviors, including delinquency, aggression, bullying perpetration and victimization, and bystander skills that lower the likelihood of violence and support victims. $^{76,77,151,154,155}$ For example, the Task Force for Community Preventive Services found a $15 \%$ relative reduction in violent behavior among students in pre-kindergarten through high school. ${ }^{151}$ Using different outcome measures, the median relative reduction in aggression and violent behavior associated with universal school-based programs varied by grade level, with a $32 \%$ reduction for pre-kindergarten and kindergarten students, $18 \%$ reduction for elementary students, $7 \%$ reduction for middle school students, and $29 \%$ reduction for high school students. Researchers suggest the benefits of these school-based approaches could be strengthened if programs implemented at early grade levels are continued into the critical high school years. ${ }^{98}$ These programs were effective in reducing youth violence in different types of school environments, including ones with varying socioeconomic status, crime rates, or predominant race/ethnicity of students. ${ }^{151}$

Examples of effective classroom-based programs are Good Behavior Game (GBG), Promoting Alternative THinking Strategies ${ }^{\circledR}$ (PATHS), Life Skills ${ }^{\circledR}$ Training (LST), and Steps to Respect (STR). The GBG has demonstrated that participants had significantly lower levels of classroom aggression in elementary school, and some studies of the long-term effects of GBG showed significantly lower levels of aggression in middle school and lower prevalence of antisocial personality disorder and violent crime by age 19 to $21 .{ }^{156-159}$ These effects were for male youth with relatively higher levels of early aggression when compared to youth in alternative intervention conditions. ${ }^{157-159}$ These participants also had lower prevalence of alcohol abuse, smoking, and suicidal ideation by the time they reached young adulthood. ${ }^{157,160}$

Multiple evaluations of PATHS show significant program impacts on aggression, violent behaviors, and a number of developmental risk factors for violent behavior among participants in both regular and special education classrooms. ${ }^{76}$ For instance, randomized controlled trials of PATHS found participants relative to controls were better able to regulate their emotions, understand social problems, develop effective solutions, and decrease their use of aggressive responses to conflict. ${ }^{161}$ At the one-year follow-up, participants also reported fewer depression symptoms and had fewer conduct problems. ${ }^{161}$ An independent randomized evaluation replication, which tracked students from 14 schools over a period of 3 years, found less self-reported aggressive problem-solving and fewer teacher-reported conduct problems among participants relative to controls. ${ }^{162}$ Relative to controls, participants also demonstrated greater reading and math proficiency in fourth grade and writing proficiency in fifth and sixth grade. ${ }^{163}$

In multiple short- and long-term randomized trials of the LST program, participants demonstrated significant improvements in social skills, such as assertiveness and self-control, and a lower prevalence of many risk behaviors, including smoking, alcohol and drug use, HIV risk behavior, and unsafe driving. ${ }^{76} \mathrm{~A}$ randomized trial of program benefits on violence outcomes across 41 schools found student participants in a one-year LST program, relative to students receiving a standard health education curriculum, reported a $32 \%$ reduction in delinquency, a $36 \%$ reduction in frequent delinquency ( $\geq 3$ events), and a $26 \%$ reduction in frequent fighting ( $\geq 3$ events). ${ }^{164}$ Stronger prevention benefits were found for youth who participated in at least half of the program, including less physical and verbal aggression, fighting, and delinquency. ${ }^{164}$ 
STR is one school-based program with demonstrated impacts on bullying and youth violence protective factors. A longitudinal evaluation of STR found after the second year of implementation, participants had a 31\% decrease in bullying and victimization, 36\% decrease in non-bullying aggression, and $72 \%$ decrease in harmful bystander behavior. ${ }^{165} \mathrm{~A}$ large scale replication evaluation found significantly lower levels of physical bullying perpetration among participants relative to controls, and significant increases in school anti-bullying policies, positive school climate, and positive bystander behavior. ${ }^{166}$

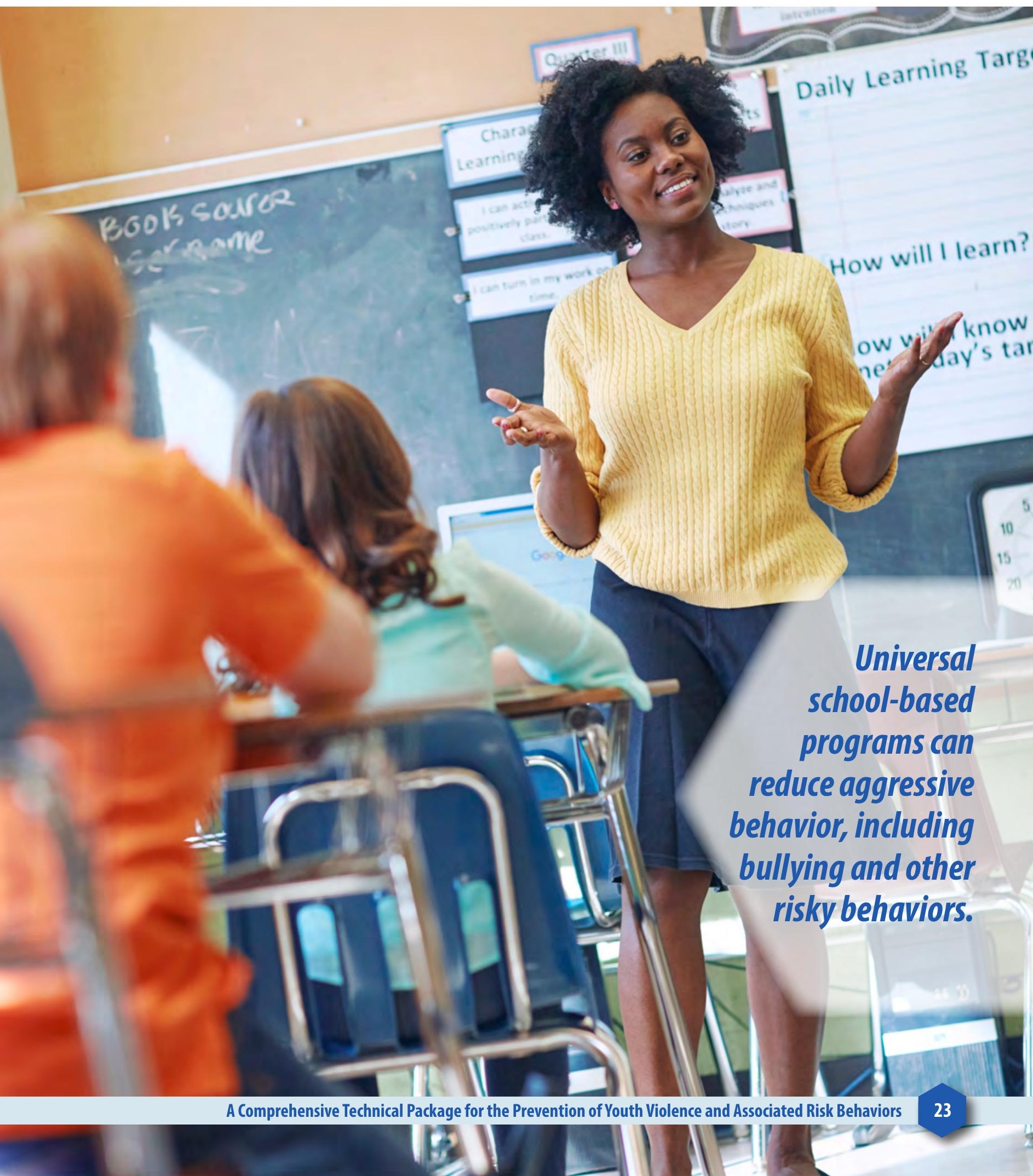




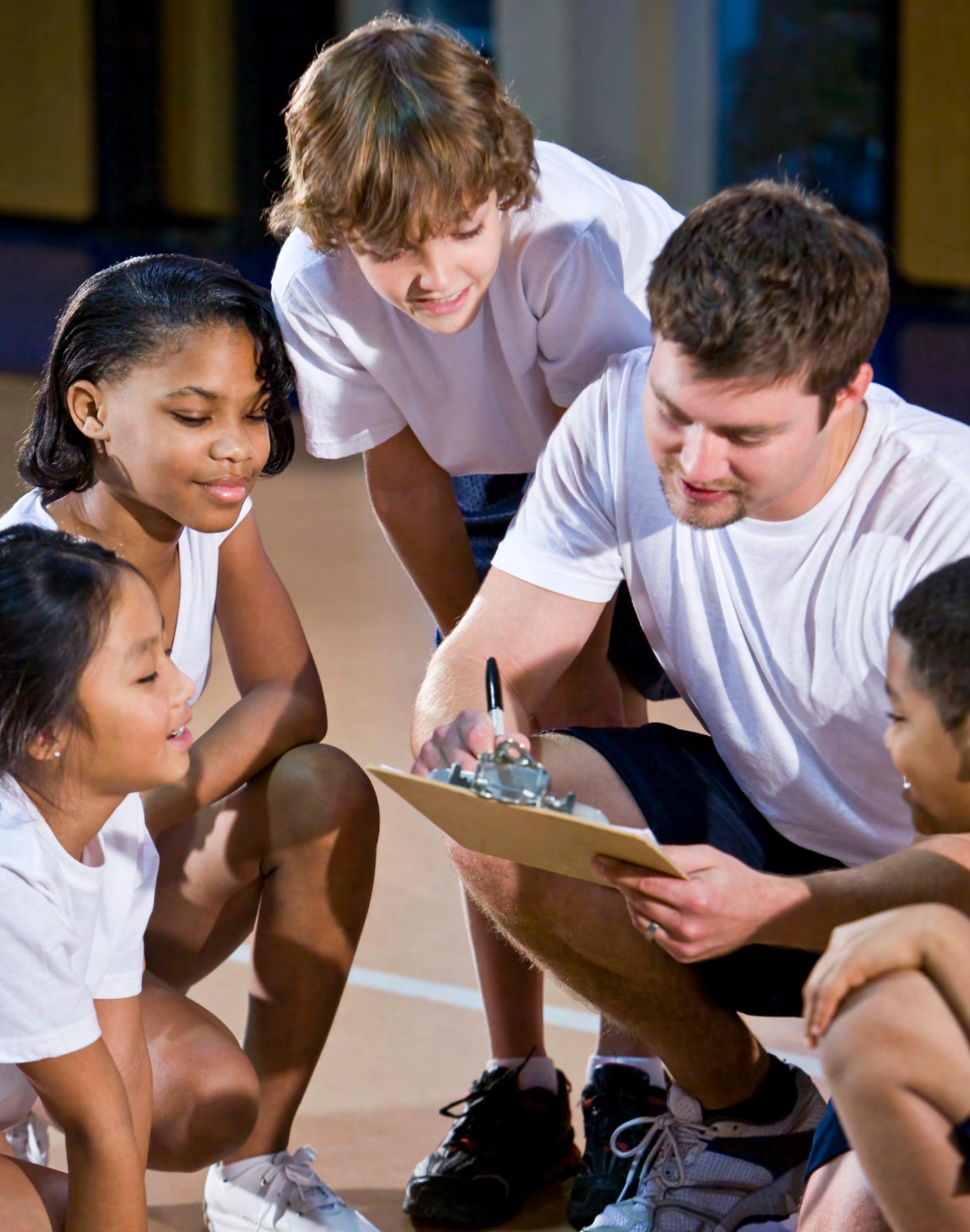




\section{Connect Youth to Caring Adults and Activities}

\section{Rationale}

Young people's risk for violence can be buffered through strong connections to caring adults and involvement in activities that help young people grow and apply new skills. ${ }^{44,53,147}$ Relationships with caring adults, in addition to parents or caregivers, can influence young people's behavioral choices and reduce their risk for involvement in crime and violence, alcohol and other substance use, and high-risk sexual behavior. ${ }^{44,53,55}$ These caring adults could include teachers, coaches, extended family members, neighbors, and community volunteers. Exposure to positive adult role models helps youth learn acceptable and appropriate behavior. ${ }^{54}$ Through positive interpersonal relationships and learning activities, youth can also develop broad and healthy life goals, improve their school engagement and skills, and establish networks and have experiences that improve their future schooling and employment opportunities. ${ }^{147}$ These connections and experiences and the many benefits they contribute to, such as enhanced academic performance, are protective against involvement in crime and violence. ${ }^{42,167}$

\section{Approaches}

Mentoring and after-school programs are two approaches for connecting youth to caring adults and engaging youth in activities to reduce or buffer against their risk for violence perpetration and victimization.

Mentoring programs pair youth with a volunteer from the community with the goal of fostering a relationship that will contribute to the young person's growth opportunities, skill development, and academic success. ${ }^{89,168}$ Mentoring programs may be delivered without any set location for mentoring activities or be implemented in a specific location, such as a community center or faith-based organization. Mentoring programs can also be implemented in school settings (e.g., volunteers meet with youth on school grounds) and include academic support and enrichment activities. ${ }^{168,169}$ Program models can involve one-to-one matching of an adult mentor with a youth or take a group mentoring approach. The level of training and support provided to mentors varies depending on the model used. Programs can varying in how similar mentors and youth are in their interests and how frequently they spend time together. ${ }^{168,169}$ Mentoring programs can be delivered to any youth from early childhood through adolescence without regard to known risk factors, although programs more typically focus on youth perceived to be at risk for problems in academics, behavior, or health. ${ }^{168}$

After-school programs provide opportunities for youth to strengthen their social and academic skills and become involved in school and community activities to expand their prosocial experiences and relationships. These approaches also address key risk and protective factors for youth violence by helping to provide supervision during critical times of the day, such as from 3:00 to 6:00 p.m. when youth crime and violence peak. ${ }^{170}$ After-school programs range from those offering tutoring and homework assistance to more formal skill-based programming and structured learning activities. ${ }^{168}$ Opportunities to develop and practice leadership, decision-making, selfmanagement, and social problem-solving skills are important components of programs that work. ${ }^{171,172}$ Afterschool programs may be offered on school grounds or in community settings. ${ }^{168}$ 
- Reductions in perpetration and victimization of violence

- Reductions in physical fighting and delinquency

- Reductions in involvement in gang activity

- Reductions in rates of arrests for violent and nonviolent crime

- Reductions in drug selling

- Reductions in alcohol and drug use

- Reductions in truancy

- Reductions in rates of school dropout

- Increases in academic performance and perceptions of academic abilities

- Increases in graduation rates

- Increases in parent-child relationships and parental trust

- Increases in positive relationships with teachers or prosocial adults

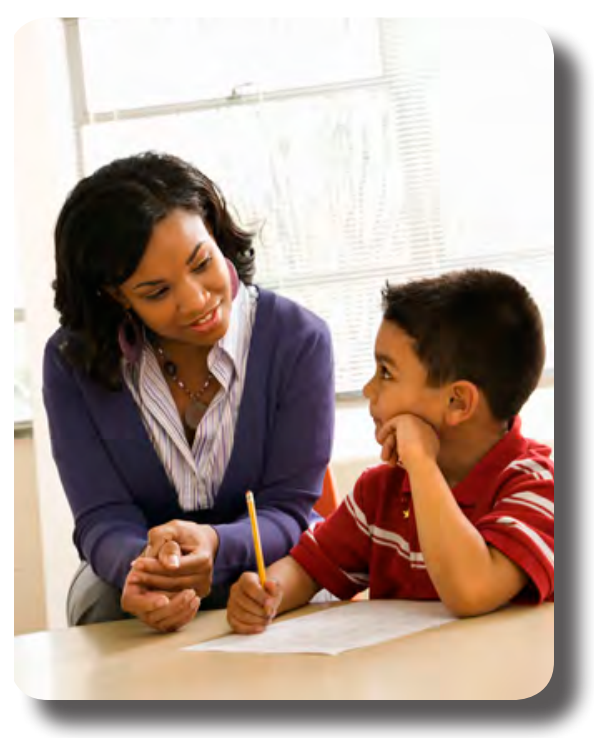

\section{Evidence}

Evidence suggests that mentoring and after-school approaches can benefit youth in a number of ways, including reducing their risk for involvement in crime and violence, although the evidence of effectiveness varies by model and program.

Mentoring programs. Systematic reviews and meta-analyses of mentoring programs show strong support for improvements in outcomes across behavioral, social, emotional, and academic domains. 53,89,169 Big Brothers Big Sisters of America (BBBS) is the oldest and best known example of a one-on-one mentoring program implemented in community and school settings in the United States. ${ }^{173}$ An evaluation of the community-based BBBS mentoring program found positive impacts on a number of problem behaviors. ${ }^{174}$ At the 18 -month follow-up, mentored youth had skipped half as many days of school as control youth and were $46 \%$ less likely to have initiated illegal drugs and $27 \%$ less likely to have initiated alcohol use, which are important risk factors for youth violence. Mentored youth were also $32 \%$ less likely to have engaged in a physical fight. Other benefits included stronger academic competence and improvements in parental trust. Although the benefits were significant for both boys and girls, many of the strongest gains were among the Little Sisters.

A national evaluation of the school-based mentoring program of $B B B S$ found that mentored youth performed better academically, had more positive perceptions of their academic abilities, and were more likely to report having a special adult in their lives for support relative to a control group of non-mentored youth-factors that protect against youth violence. ${ }^{175}$ Impacts on other youth outcomes were influenced by relationship factors. Higher-quality mentoring relationships were associated with improvements in parental and student-teacher relationships. ${ }^{176}$ These, in turn, were associated with better youth outcomes, such as increased prosocial behavior and decreases in problem behaviors, such as getting into a physical fight in the neighborhood and vandalizing property. ${ }^{176}$ 


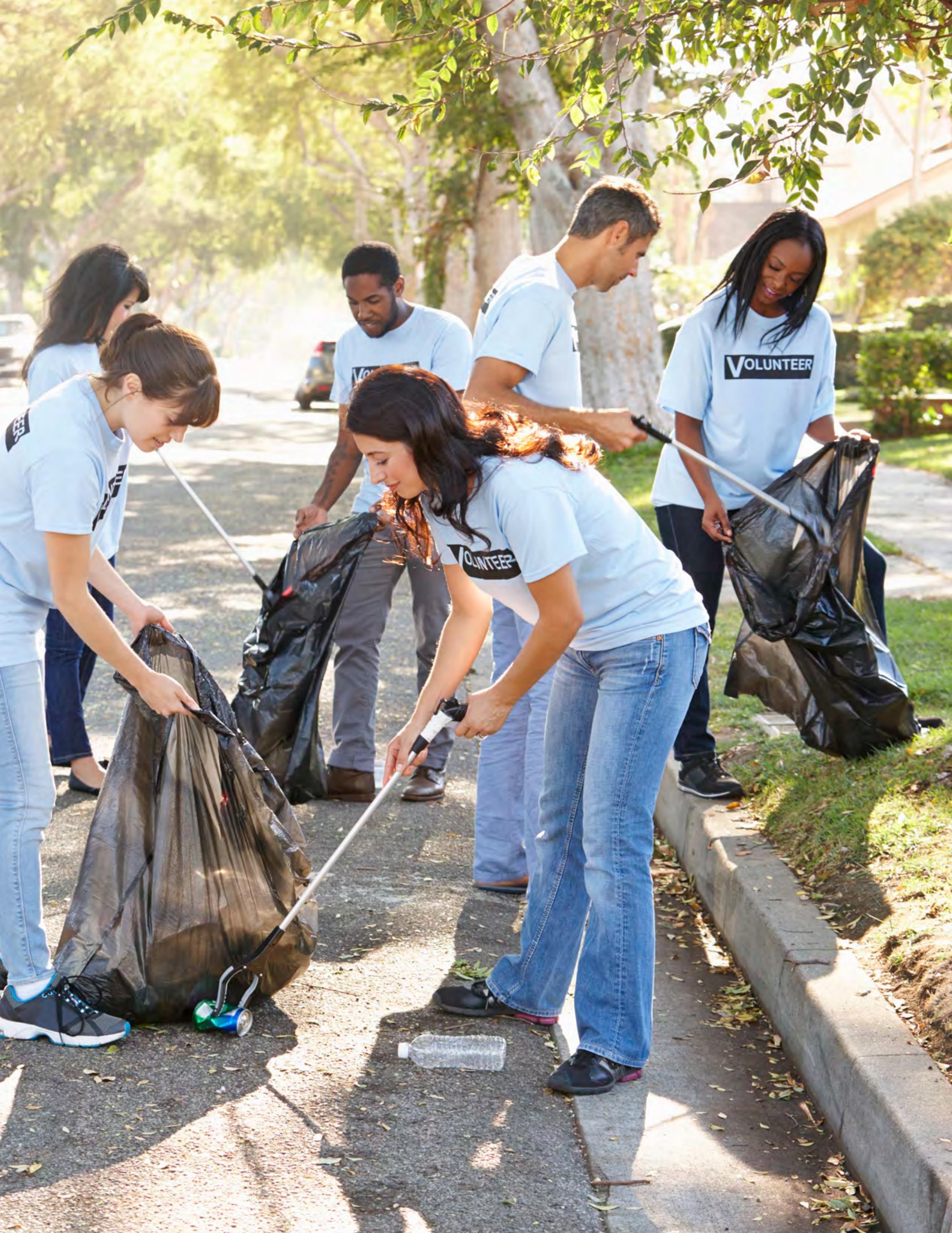




\section{Create Protective Community Environments}

\section{Rationale}

Creating protective community environments in which young people develop is a necessary step towards achieving population-level reductions in youth violence. Communities can include places with any defined population with shared characteristics and environments, such as schools, towns, cities, youth-serving organizations or institutions, and areas (e.g., parks, business districts, public transportation hubs) where individuals regularly interact. Approaches that modify the characteristics of these places are considered community-level approaches. Such approaches can involve, for example, changes to policies or the physical and social aspects of settings in order to reduce risk factors and increase protective factors for youth violence. ${ }^{1}$ These changes can have a significant influence on individual behavior by creating a context that promotes social norms that protect against violence. ${ }^{182}$ These approaches can improve perceived and actual safety and reduce opportunities for violence and crime and, in turn, increase protective factors, such as residents having more prosocial interactions and opportunities to support youth. Approaches that create protective environments can reduce violence-related injury and death as well as have long-term benefits by reducing children's exposure to violence and the consequences of this exposure. ${ }^{39,183}$

\section{Approaches}

The current evidence suggests three approaches with promise for modifying the characteristics of settings associated with youth violence victimization and perpetration.

Modify the physical and social environment. These approaches prevent youth violence and crime by enhancing and maintaining the physical characteristics of settings where people come together in order to foster social interaction, strengthen connectedness, and increase collective efficacy (e.g., shared trust among residents and willingness to intervene).$^{56-58}$ Examples of this work include increasing lighting, managing accessibility to buildings and public spaces, street cleaning, increasing security, abandoned building and vacant lot remediation, creating green space, and sponsoring community events that bring residents together. These approaches can also be applied in school and other settings where young people frequently interact. ${ }^{184-187}$ These approaches are often led by governmental and nongovernmental community partners (e.g., city planners, parks and recreation, business) and may include youth and adult residents.

Reduce exposure to community-level risks. Youth violence is associated with a number of community-level risks, such as concentrated poverty, residential instability, and density of alcohol outlets. ${ }^{33,37,61,63}$ Reducing exposure to these community-level risks can potentially yield population-level impacts on youth violence outcomes. ${ }^{188}$ Prevention approaches to reduce these risks include changing, enacting, or enforcing laws, city ordinances and local regulations, and policies to improve household financial security, safe and affordable housing, and the social and economic sustainability of neighborhoods. Public-private partnerships and community-driven needs and services are important elements of these approaches.

Street outreach and community norm change approaches connect trained outreach staff with residents to mediate conflicts, promote norms of nonviolence, and connect youth to community supports to reduce risks and build buffers against violence. ${ }^{183}$ The ways in which these connections occur can vary depending on the model used, outreach staff training and expertise, and available community resources. Outreach staff typically connect with residents with known histories of engaging in criminal and violence-related activities or who are at heighten risk to engage in violence (e.g., had a recent argument, family member or friend recently harmed by violence). This approach also uses public education and neighborhood events to change norms about the acceptability of violence and willingness of community members to act in ways to reduce the likelihood of violence. 


\section{$-\infty$}

- Reductions in nonfatal physical assault, firearm assaults, nonfatal shootings, and homicide

- Reductions in violence-related injuries among youth

- Reductions in nonviolent and violent crime and arrests

- Reductions in gang-related violence

- Reductions in community risk factors for youth violence (e.g., alcohol use by minors)

- Reductions in acceptability of using guns to resolve disputes

- Increases in normative beliefs that violence is unacceptable

\section{Evidence}

The evidence supporting these approaches is growing and shows significant impacts on neighborhood crime and youth violence. ${ }^{77,189}$

Modify the physical and social environment. Evaluations of physical and social environment approaches demonstrate significant decreases in crime and violence in neighborhood settings. For example, Business Improvement Districts (BIDs) are public-private partnerships that collect and invest resources from local merchants and property owners into local services and activities, such as efforts to improve commercial activity, street cleaning and beautification, and public safety, in order to increase appeal and use by residents and the prosperity of the businesses and community. An evaluation of BIDs in Los Angeles found a $12 \%$ reduction in robberies and $8 \%$ reduction in overall violent crime in BID neighborhoods compared to the non-exposed neighborhoods as well as significant economic benefits due to reduced crime rates, reduced arrests, and lower prosecution-related expenditures. ${ }^{78,190}$ Environmental design activities, such as Crime Prevention Through Environmental Design (CPTED), promote positive interpersonal interactions and the safe use of spaces through enhanced visibility, access management, and proper maintenance and design.${ }^{56} \mathrm{~A}$ systematic review of CPTED principles applied to business settings found significant reductions in robberies. ${ }^{191}$ Evaluations and a systematic review also show communities applying some CPTED principles, such as abandoned building and vacant lot remediation and cleaning and maintenance of neighborhood green spaces and housing, experience decreases in gun assaults, youth homicide, disorderly conduct, and violent crime as well as beneficial impacts on residents' perception of crime, stress, community pride, and physical health. ${ }^{192-197}$

Reduce exposure to community-level risks. Strengthening household financial security through tax credits, such as the Earned Income Tax Credit (EITC), can help families increase their income while incentivizing work or offsetting the costs of child-rearing and help create home environments that promote healthy development. ${ }^{198}$ While the EITC has not been evaluated for its direct impact on rates of youth violence, the evidence suggests that the EITC can lift families out of poverty. ${ }^{199,200}$ Simulations show that a Child Tax Credit of a $\$ 1000$ allowance per child, paid to each household regardless of income or tax status, would reduce child poverty in the United States from $26.3 \%$ to $23.2 \%$; a $\$ 2000$ allowance per child would reduce child poverty to $20.4 \%$; a $\$ 3000$ allowance per child would reduce child poverty to $17.6 \%$; and a $\$ 4000$ allowance per child would reduce child poverty to $14.8 \%{ }^{201}$ The Low-Income Housing Tax Credit (LIHTC), which is designed to improve the availability of safe and affordable rental housing in highly distressed urban neighborhoods, can help revitalize the poorest neighborhoods and offset a number of negative outcomes in these communities. ${ }^{59}$ There is evidence suggesting that the LIHTC can reduce the concentration of poverty and is also associated with reductions in violent crime and aggravated assault without evidence of spatial displacement. ${ }^{59,202}$

Evaluations of other strategies to reduce exposure to community-level risks are emerging, with policies related to alcohol receiving substantial attention. Systematic reviews and meta-analyses show alcohol policies (e.g., location and concentration of outlets, licensing regulations, pricing, hours and days of sale) can influence risk factors associated with youth violence and other health conditions. ${ }^{203-205}$ An evaluation of a Richmond, Virginia policy restricting licenses for the sale of single-serve alcoholic beverages by convenience stores found significant declines in ambulance pickups of youth for violent injuries (19.6 to 0 per 1,000 ) as compared to a control community $(7.4$ to 3.3 per 1,000$) .{ }^{206}$ International studies also demonstrate policies related to alcohol sales are associated with significant reductions in homicide, physical assaults, and violent crime. ${ }^{207-209}$ 
Street outreach and community norm change. Several types of street outreach and community norm change programs exist, and some have evidence to support their effectiveness in preventing violence. Cure Violence (formerly known as Ceasefire), and similar programs, such as Baltimore's Safe Streets, have been implemented and evaluated in several communities. These programs are associated with reductions in gun violence, homicides, gangrelated violence, and nonfatal assault-related injuries in some but not all implementation areas where studied. ${ }^{183} \mathrm{An}$ evaluation of Chicago's Cure Violence implemented in seven communities found significant reductions in aggravated batteries and assaults and shootings in half of the implementation communities while the other implementation communities either had no significant declines or no differences in the rate of decline relative to the comparison communities. ${ }^{210}$ An evaluation of Baltimore's Safe Streets program in four neighborhoods found significant reductions in nonfatal shootings in the four implementation areas, significant reductions in homicide in two implementation areas, and either no reduction or an increase in homicides in two implementation areas relative to comparison communities. The impacts on homicide and nonfatal injuries also extended to the neighborhoods surrounding the implementation sites. Across all the implementation sites and bordering areas, the combined prevention effects were at least 5 fewer homicides and approximately 35 fewer nonfatal shootings. ${ }^{182}$ Across the implemented programs and evaluations, investigators suggest mixed effects may be related to variations in the outreach workers, how well the program is managed and implemented, and other community contextual factors, such as shifts in gang violence and support from neighborhood organizations. ${ }^{182,183}$

An additional goal of these programs is to change community norms about the acceptability of violence. The evaluation of Safe Streets on youth's attitudes found youth in one intervention community were 4 times less likely than youth in a nonintervention comparison neighborhood to support the use of a gun to resolve disputes. ${ }^{211}$ Another evaluation shows one year after the implementation of Safe Streets, youth in the intervention community relative to the control community had significant changes in their attitudes about the use of gun violence to resolve conflicts, with intervention youth viewing violence to solve conflicts less favorably. ${ }^{60}$

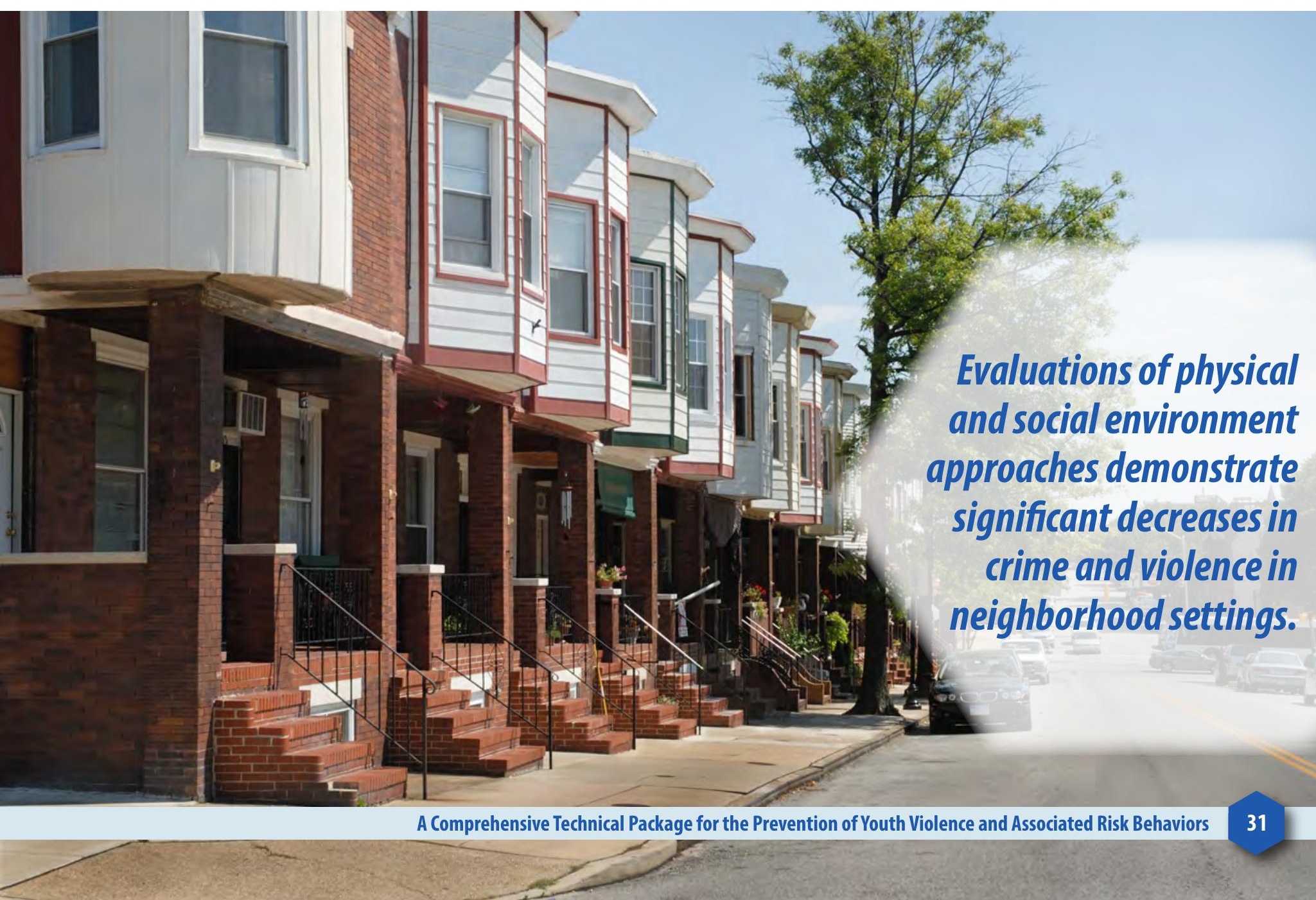




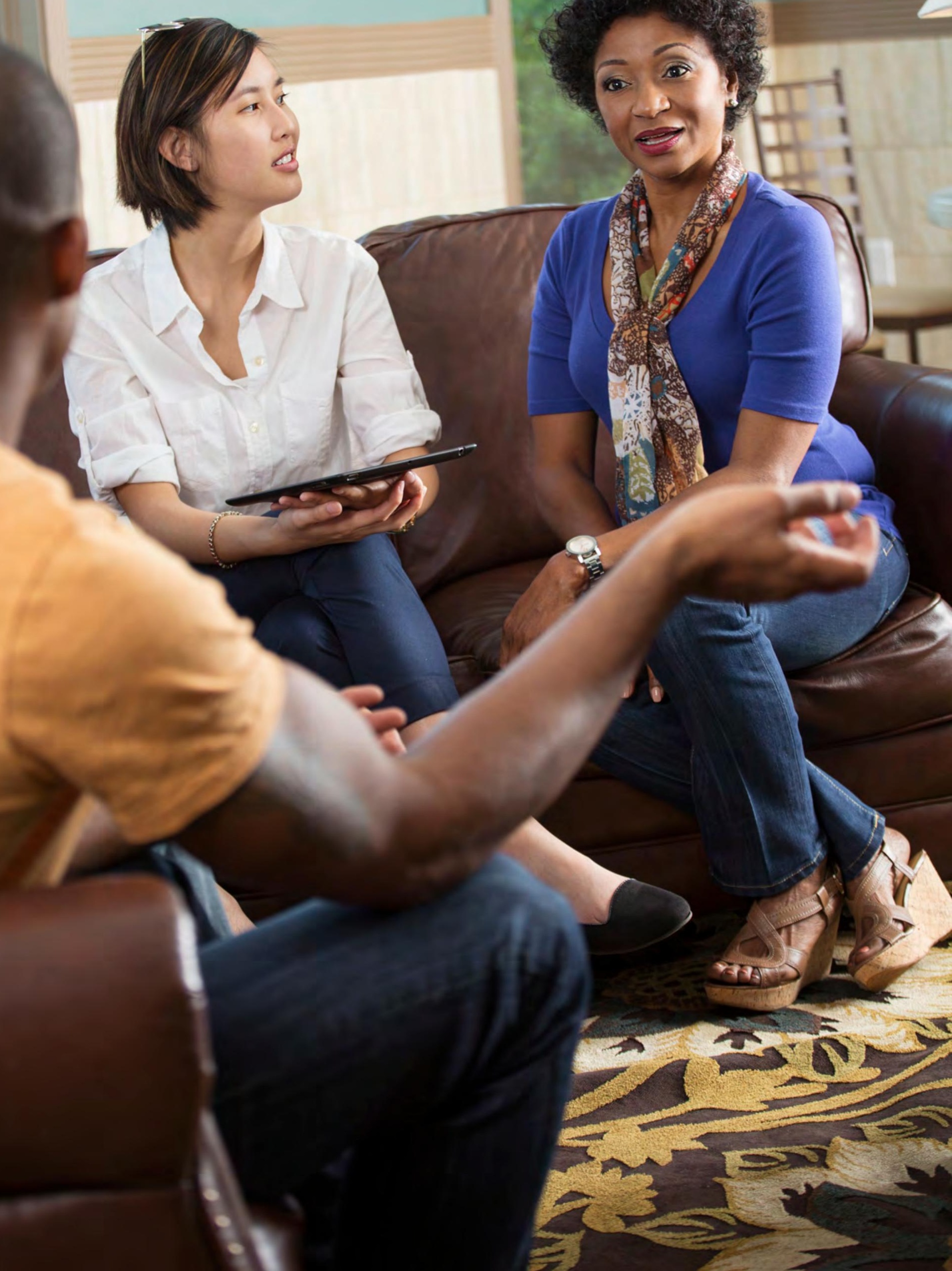




\section{Intervene to Lessen Harms and Prevent Future Risk}

\section{Rationale}

Many youth who engage in violence as teens and young adults have histories of childhood conduct problems, aggression, violence perpetration and victimization, delinquency, and criminal behavior. ${ }^{20,33,212-214}$ These youth often have other known risk factors for violence, including substance use, academic problems, associations with deviant peers, and home environments characterized by disruption, conflict, violence, and other family problems. ${ }^{20,33,215}$ Many have experienced traumatic events and show signs of behavioral and mental health problems from experiencing, witnessing, and living with chronic exposures to violence and in unhealthy environments. ${ }^{15,216,217}$ Justice responses, such as incarceration alone, have limited effect on youths' future criminal behavior, and some policies, such as the transfer of juvenile offenders to adult criminal courts, can result in worse outcomes for youth. 15,28-30,218 Other approaches designed to address these youths' many risk factors have the potential to interrupt the continuation and escalation of violence. ${ }^{2,49,219,220}$ These interventions can also create resiliency and strengthen familial protective factors, such as parental monitoring, parent-child communication, and behavioral management.

\section{Approaches}

Several approaches have been identified to lessen the harms of violence exposure and prevent the continuation and escalation of violence and its associated risk factors, including therapeutic treatments and hospital-community partnerships that provide brief intervention and community prevention services.

Treatment to lessen the harms of violence exposures. Therapeutic treatment can mitigate the behavioral and health consequences of witnessing or experiencing violence in the home and community and other adverse child experiences. ${ }^{221-224}$ Improvements can occur in youth's maladaptive and acting out behaviors, irritability, difficulty sleeping or concentrating, and symptoms of depression, anxiety, and post-traumatic stress disorder (PTSD). Treatments are designed to help youth process traumatic exposures, manage trauma-related distress, and develop effective coping strategies and skills. These treatments are typically delivered by trained professionals in a one-on-one or group setting and over the course of 12 or more sessions. Referrals may come from social services, schools, or other local community organizations. Treatment is often provided to children at varying ages and stages of development, and as such, may engage both the child and caregiver in the treatment process.

Treatment to prevent problem behavior and further involvement in violence simultaneously addresses multiple risk factors and builds supports at home and in the community. These approaches develop youth's social and problem-solving skills, provide youth with therapeutic services to address behavioral and emotional issues, offer families therapeutic services to reduce conflict, improve communication, and enhance parents' management and supervision of youth. ${ }^{49,219,220}$ The goal of these supports is to assist youth and families in making significant changes in their behavior in order to prevent youth from engaging in future acts of violence. Referrals may come from the juvenile justice system, schools, or other community organizations working with young people and families who have many risk factors for youth violence. Programs are often delivered by trained clinicians in the home or a clinic setting and can be administered to individual families or groups of families. Programs typically include multiple components, such as individual counseling of youth, family counseling, parent training, and school consultation. 


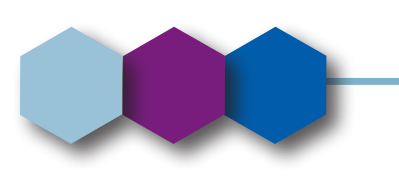

Hospital-community partnerships are intended to strengthen connections between the acute treatment of violence-related injuries and community assistance in order to prevent future injuries and health risk behaviors. ${ }^{225}$ These approaches provide support to youth shortly after receiving care in emergency departments for acute issues. The youth served by these approaches and the length and content of the program vary based on the model used. Typically these programs involve brief interventions to develop skills and risk awareness, needs assessments, and connection to case-management services. Motivational interviewing to engage youth and encourage behavior change, components to address peer norms about risk behaviors, and ways to manage life stressors and situations post-injury are elements of these interventions. ${ }^{226}$

\section{Potential Outcomes}

- Reductions in victimization and perpetration of violence

- Reductions in nonviolent and violent crime

- Reductions in arrests and recidivism

- Reductions in gang involvement

- Reductions in out-of-home placements

- Reductions in siblings' criminal behavior

- Reductions in teen dating violence

- Reductions in child abuse

- Reductions in substance use

- Reductions in symptoms of PTSD, depression, and behavioral problems

- Increases in school attendance and homework completion

- Increases in positive parenting and family management practices (e.g., monitoring and supervision)

- Improvements in family relationships and communication

\section{Evidence}

A large body of evidence highlights the importance and benefits of intervening with youth who have histories of violence, crime, and delinquency exposures.

Treatment to lessen the harms of violence exposures, such as Trauma-Focused Cognitive Behavioral Therapy ${ }^{\circledR}$ (TF-CBT), is effective in reducing symptoms of PTSD, depression, and behavioral problems as well as strengthening positive parenting practices. ${ }^{221,227}$ TF-CBT was originally designed to address symptoms associated with sexual abuse and has been adapted to treat other traumas including witnessing community or domestic violence, which are important risk factors for youth violence. ${ }^{228}$ Another example, Cognitive Behavioral Intervention for Trauma in Schools (CBITS), is designed for youth ages 10-15.229 This program addresses treatment barriers, such as stigma and access to services, by offering the treatment in school settings but has also been implemented in community settings with a range of populations (e.g., ethnic minority, immigrant, low and middle-income). The treatment is associated with improvements in symptoms of PTSD and depression and parent-reported behavioral problems. ${ }^{230}$

Treatment to prevent problem behavior and further involvement in violence. The benefits of therapeutic interventions for young people with histories of violence, crime and delinquency have been documented in numerous reviews. ${ }^{49,219,220}$ One meta-analysis of interventions for youth with a history of criminal offenses found that relative to controls juveniles who received treatment had an average $12 \%$ decrease in future violence and crime. ${ }^{220}$ Across studies, larger effects were found for more serious offenders (e.g., history of both person and property offenses) than less serious offenders and when the treatments were longer. However, the effects of individual programs varied with some programs having more substantial impacts (e.g., $40 \%$ reduction in recidivism) and others associated with no effects or an increase in recidivism. Examples of programs demonstrating benefits for participating youth and families include Functional Family Therapy (FFT), Multidimensional Treatment Foster Care (MTFC), and Multisystemic Therapy ${ }^{\circledast}$ (MST). 
FFT is a short-term, family-focused program that strengthens parentchild communication and relationships and helps families set clear expectations and use consequences to improve youth's behavior. Evaluations of FFT have shown significantly lower recidivism in misdemeanor and felony offenses among participating youth relative to youth receiving only probation during adolescence ( $11 \%$ versus $67 \%)$ and young adulthood (9\% versus $41 \%) .{ }^{231,232}$ Other evaluations have replicated the impact on recidivism in domestic and international samples and also demonstrated other positive outcomes, including stronger family communication, improved family mental health, reduced court involvement of siblings, and lower substance use by youth. ${ }^{233-235}$

MTFC includes short-term placements of chronically delinquent youth with extensively trained foster parents, family therapy for biological parents, and behavioral and academic supports to youth. A systematic review of therapeutic foster care approaches, such as MTFC, demonstrates an approximate $72 \%$ reduction in violent crimes among participants. ${ }^{236}$ Relative to youth in usual care services, MTFC participants also had significantly lower self-reported violence and fewer referrals for violent crime (5\% versus $24 \%$ ) two years post intervention. ${ }^{237}$ Other benefits include lower substance use, improvement in family management practices, and stronger school attendance and homework completion. ${ }^{238,239}$

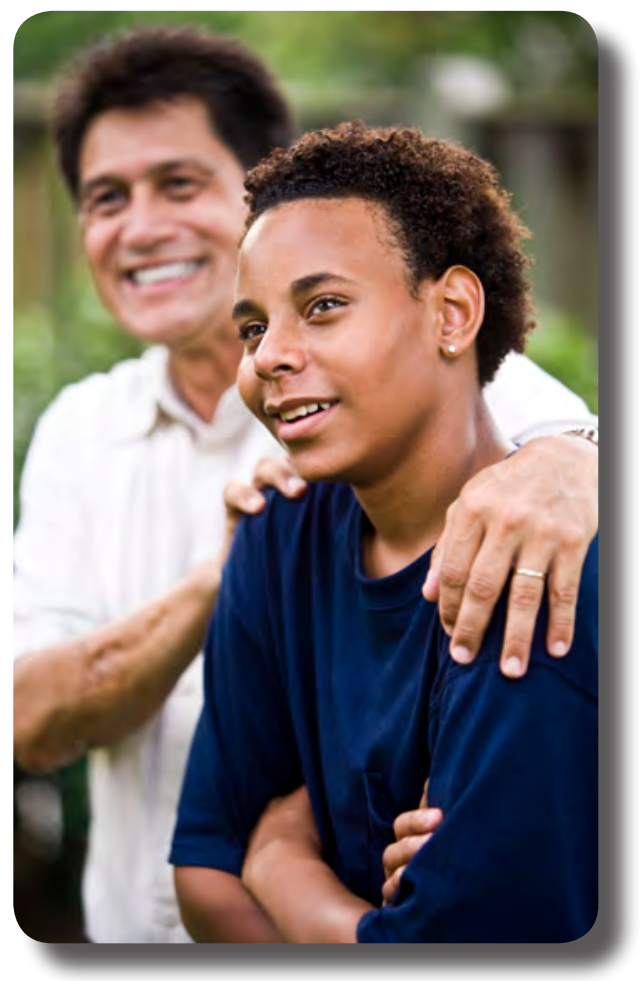

MST is an intensive multi-component program for chronically delinquent and violent youth that engages the youth's entire social network (e.g., family, school and teachers, neighborhood, friends) in order to reduce risks and improve protective factors. MST has been evaluated in numerous trials with samples of chronic and violent juveniles. ${ }^{240}$ These studies demonstrate significant long-term reductions in re-arrests (reduced by a median of $42 \%$ ) and out-of-home placements (reduced by a median of 54\%), as well as beneficial impacts on family functioning and positive parenting practices, youth's substance use, youth's behavioral and mental health, youth's gang involvement, and sibling's criminal behavior. ${ }^{240,241}$ For example, MST participants relative to youth receiving individual therapy had fewer violent felony arrests approximately 22 years later (4.3\% versus $15.5 \%)$, and the siblings of these participants had fewer arrests for any crime (43.3\% versus $72 \%)$ and felonies (15\% versus $34 \%)$ approximately 25 years later. ${ }^{242,243}$ Other benefits include improvements in positive parenting practices, reductions in child abuse, lower substance use, and community cost savings. ${ }^{240}$

Hospital-community partnerships. The implementation of brief emergency department interventions is growing across the United States. ${ }^{244}$ Some of these interventions have also been rigorously evaluated to assess their effects on revictimization, substance use, further involvement in crime and violence, and rates of entry or re-entry into the criminal justice system. ${ }^{245-247}$ For instance, SafERteens is an emergency department intervention for youth who present with violence or alcohol use problems that uses motivating interviewing techniques to increase problem recognition and skills, including conflict resolution, alcohol refusal, and anger management. Evaluations of SafERteens demonstrate that participating youth relative to controls had significant reductions in perpetration and victimization of peer violence that were maintained one-year following the intervention. ${ }^{248}$ Additional program benefits include reductions in alcohol use and dating violence victimization. ${ }^{246,249}$ SafERteens has been adapted to include content applicable to youth regardless of their history of violence or alcohol use, and an evaluation of the adapted model (Project SYNC) also demonstrated a significant decrease in the frequency of perpetrating violence and an increase in self-efficacy to avoid fighting among participating youth relative to controls. ${ }^{250}$ An evaluation of the Caught in the Crossfire program in Oakland, California yielded positive outcomes on youths' involvement in crime. During the sixmonth post-injury evaluation period, the intervention youth were $70 \%$ less likely to be arrested for any offense and $60 \%$ less likely to have had any involvement in the criminal justice system compared with controls. ${ }^{245}$ 


\section{Benefits Relative to Costs}

A robust evidence base of effective prevention approaches has enabled researchers to systematically assess the benefits relative to costs of many youth violence prevention activities. Many prevention programs and policies presented in this technical package have been shown in one or more studies to have significant preventive effects on youth violence or risk and protective factors for youth violence as well as have economic benefits that exceed implementation costs. ${ }^{76,78-80}$ Published cost-benefit estimates can vary as researchers and states calculating the economic benefits of programs can differ in their methods, such as focusing on a single program versus multiple programs, the rigor of included research, and costs and outcomes considered. ${ }^{251,252}$ The table below includes examples of benefit-cost information for some of the programs in this technical package based on Washington State's methodology of estimating cost-benefits. Washington State's approach considers program impacts on factors and systems, including future labor market earnings, criminal justice costs, education system costs, and health care expenses.

\section{Estimates of Benefits Relative to Costs*}

\begin{tabular}{|l|l|}
\hline Evidence-based Approach/Program & Benefits per \$1 of cost \\
\hline Nurse Family Partnership ${ }^{\circledR}$ & $\$ 1.61$ \\
\hline The Incredible Years $^{\circledR}$ - Parent & $\$ 1.65$ \\
\hline Strengthening Families 10-14 & $\$ 5.00$ \\
\hline Early Childhood Education Programs (state and district) & $\$ 5.05$ \\
\hline Good Behavior Game & $\$ 64.18$ \\
\hline Life Skills ${ }^{\circledR}$ Training & $\$ 17.25$ \\
\hline Mentoring (school-based) & $\$ 14.85$ (with volunteer cost) \\
\hline Functional Family Therapy & $\$ 23.86$ (taxpayer only) \\
\hline Multidimensional Treatment Foster Care & $\$ 1.70$ \\
\hline Multisystemic Therapy & $\$ 1.74$ \\
\hline
\end{tabular}

*Dollar estimates by Washington State Institute for Public Policy are in 2015 dollars and are specific to the state of Washington. Estimates are likely to vary across states and communities. The benefit-cost estimates are continually updated, and cost estimates presented are based on information published by Washington State Institute for Public Policy as of September 2016. The latest information is available online at: http://www.wsipp.wa.gov. 


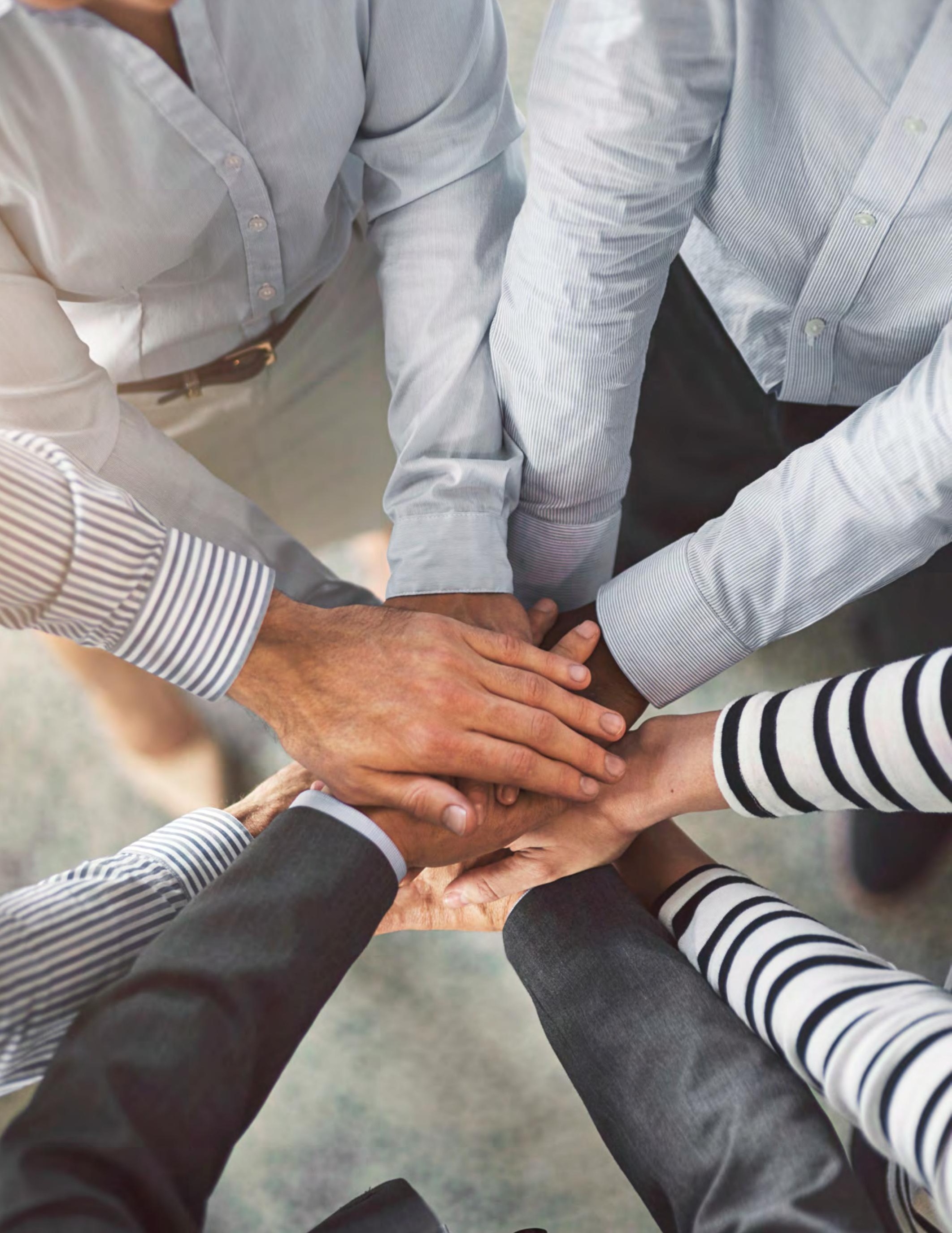




\section{Sector Involvement}

Public health can play an important and unique role in preventing youth violence. Public health agencies, which typically place prevention at the forefront of efforts and work to create broad population-level impact, can bring critical leadership and resources to bear on this problem. ${ }^{1,253}$ For example, these agencies can serve as a convener, bringing together partners and stakeholders to plan, prioritize, and coordinate youth violence prevention activities. Public health agencies are also well positioned to collect and disseminate data, implement preventive measures, evaluate programs and policies, and track progress. Although public health can play a leadership role in preventing youth violence, the strategies and approaches outlined in this technical package cannot be accomplished by the public health sector alone.

Other sectors vital to implementing this package include, but are not limited to, education, health care (mental, behavioral, medical), justice, government (local, state, and federal), social services, business, housing, media, and organizations that comprise the civil society sector, such as faith-based organizations, youth-serving organizations, foundations, and other non-governmental organizations. Collectively, these sectors can make a difference by collaborating to prevent youth violence by impacting the various contexts and underlying risks that contribute to youth violence. ${ }^{254,255}$ The selection and implementation of prevention strategies and approaches by these sectors can also be informed and strengthened by youth, families, and other community adults all of whom have important roles in preventing youth violence. ${ }^{1,15}$

The strategies and approaches described in this technical package are summarized in the Appendix along with the relevant sectors that are well positioned to lead implementation efforts. For instance, the social services, education, and public health sectors are vital for the implementation and continued provision of Quality Education Early in Life. As the lead sector in implementing programs, such as Child-Parent Centers and Early Head Start throughout the country, the social services sector is helping to ensure that families and communities receive the skills and services necessary to promote the physical, cognitive, social, and emotional development of children, thereby preparing youth for long-term academic success and positive behavioral and health outcomes. Some of these programs extend into the elementary school years making the education sector an important partner in prevention. The public health sector can play a vital role by educating communities and other sectors about the importance of ensuring early childhood education and continuing research that documents the benefits of early childhood education on health and development, family well-being, and youth violence prevention, as this evidence is important in making the case for continued support of these programs for children and families in need.

The approaches and programs that Strengthen Youth's Skills are often implemented in the education setting, making education an important sector for implementation. Public health departments across the country often work in partnership with school districts to implement and evaluate prevention programs in school settings. Some of these programs may also be suitable for delivery in community settings, and local and state public health departments can also play a leadership role in implementing and evaluating these programs in other settings. Programs to Promote Family Environments that Support Healthy Development are implemented in a variety of settings and involve the collaborative work of public health, community organizations, and education. As with other prevention programs, local and state public health departments can bring partners together to plan, prioritize, and coordinate prevention efforts and play a leadership role in evaluating these programs and tracking their impact on health, behavioral, and other outcomes. 


\section{Monitoring and Evaluation}

Monitoring and evaluation are necessary components of the public health approach to prevention. Timely and reliable data are necessary to monitor youth violence and its related risk and protective factors and to evaluate the impact of prevention efforts. Data are also necessary for prevention planning and implementation.

Surveillance data help researchers and practitioners track changes in the burden of youth violence. Surveillance systems exist at the national, state, and local levels. It is important to assess the availability of surveillance data and data systems across these levels to identify and address gaps in the systems and to utilize this information when implementing and evaluating prevention activities. The National Violent Death Reporting System (NVDRS), National Electronic Injury Surveillance System-All Injury Program (NEISS-AIP), and the Youth Risk Behavior Surveillance System (YRBSS) are examples of surveillance systems that include data on youth violence. The NVDRS is a state-based surveillance system that combines data from death certificates, law enforcement reports, and coroner or medical examiner reports to provide detailed information on the circumstances of violent deaths, including youth homicides, which can assist communities in guiding prevention approaches. ${ }^{256}$ The NEISS-AIP provides nationally representative data about all types and causes of nonfatal injuries treated in U.S. hospital emergency departments, including those related to youth violence, and can be used to characterize and monitor trends in nonfatal injuries involving youth and inform program and policy decisions. ${ }^{6}$ The YRBSS collects information from a nationally representative sample of 9-12 grade students and is a key resource in monitoring health-risk behaviors among youth, including physical fighting on and off school property, bullying, and weapon carrying. ${ }^{257}$ The YRBSS data are obtained from a national school-based survey conducted by CDC as well as state, territorial, tribal, and large urban school district surveys conducted by education and health agencies.

National, state, and local data about juvenile's violent offenses, victimization, and involvement with the justice system are also available from the Department of Justice's Bureau of Justice Statistics, the Federal Bureau of Investigation Uniform Crime Reports, and the Office of Juvenile Justice and Delinquency Statistical Briefing Book. ${ }^{9,258,259}$ State and local data from police incident reports, 911 calls, ambulance and medical services, and school disciplinary reports may also be available. Many communities and schools also conduct surveys about youth's behavior and the strengths and needs of organizations serving youth to monitor youth violence and to inform ongoing and future prevention activities.

It is important at all levels (national, state, and local) to track progress of prevention efforts and evaluate the impact of those efforts, including the impact of this technical package. Evaluation data, produced through program and policy implementation and monitoring, are essential to knowing what does and does not work to affect rates of youth violence and associated risk and protective factors. Theories of change and logic models that identify short, intermediate, and long-term outcomes are an important part of program and policy evaluation. Understanding how approaches are being implemented and what implementation conditions result in the best outcomes can inform the refinement of a community's prevention activities over time.

The evidence base for youth violence prevention has advanced greatly over the last few decades, resulting in strong evidence for strategies that address many individual and relationship risk and protective factors. More research is needed to strengthen the evidence for strategies that address community risk and protective factors for violence, reduce minors' inappropriate access to and use of weapons, and youth's risk for lethal violence. ${ }^{88,90}$ Most existing evaluations focus on approaches implemented in isolation. However, research is growing about the likely synergistic effects of using a combination of the strategies and approaches, many of which are included in this package, and results are encouraging ${ }^{82,260}$ Continued research is needed to understand the extent to which combinations of strategies and approaches result in greater reductions in youth violence than individual programs, practices, or policies. As evidence related to a strategy or approach or combination continues to grow and research gaps are filled, this technical package can be refined to reflect the latest knowledge and understanding of what works to prevent youth violence. 


\section{References}

1. David-Ferdon, C., \& Simon, T. R. (2014). Preventing youth violence: Opportunities for action. Atlanta, GA: Centers for Disease Control and Prevention. Retrieved from http://www.cdc.gov/violenceprevention/youthviolence/opportunities-for-action.html.

2. U.S. Department of Health and Human Services (2001). Youth violence: A report of the surgeon general. Rockville, MD: U.S. Department of Health and Human Services, Centers for Disease Control and Prevention, National Center for Injury Prevention and Control; Substance Abuse and Mental Health Services Administration, Center for Mental Health Services; National Institutes of Health, National Institute of Mental Health.

3. Frieden, T. R. (2014). Six components necessary for effective public health program implementation. American Journal of Public Health, 104(1), 17-22.

4. Dahlberg, L. L., \& Krug, E. G. (2002). Violence: A global public health problem. In E. G. Krug, L. L. Dahlberg, J. A. Mercy, A. B. Zwi, \& R. Lozano (Eds.), World report on violence and health (pp. 1-56). Geneva, Switzerland: World Health Organization.

5. Mercy, J., Butchart, A., Farrington, D., \& Cerdá, M. (2002). Youth violence. In E. G. Krug, L. L. Dahlberg, J. A. Mercy, A. B. Zwi, \& R. Lozano (Eds.), World report on violence and health (pp. 25-56). Geneva, Switzerland: World Health Organization.

6. Centers for Disease Control and Prevention. (2016). Web-based Injury Statistics Query and Reporting System (WISQARS). Atlanta, GA: Centers for Disease Control and Prevention, National Center for Injury Prevention and Control. Retrieved from http://www.cdc.gov/injury/wisqars/.

7. Centers for Disease Control and Prevention. (2016). Youth online: High school YRBS. Atlanta, GA: Centers for Disease Control and Prevention, National Center for Chronic Disease Prevention and Health Promotion. Retrieved from http://www.cdc.gov/ healthyyouth/data/yrbs/.

8. David-Ferdon, C., Dahlberg, L. L., \& Kegler, S. (2013). Homicide rates among persons aged 10-24 years - United States, 19812010. Morbidity and Mortality Weekly Report, 62(27), 545-548.

9. Federal Bureau of Investigation. (2015). Uniform crime reports: 2014 Crime in the United States. Washington, DC: U.S.

Department of Justice, Federal Bureau of Investigation. Retrieved from https://www.fbi.gov/about-us/cjis/ucr/crime-in-theu.s/2014/crime-in-the-u.s.-2014.

10. Office of Juvenile Justice and Delinquency Prevention. (2016). National youth gang survey analysis. Washington, DC: U.S. Department of Justice, Office of Justice Programs, Office of Juvenile Justice and Delinquency Prevention. Retrieved from https://www.nationalgangcenter.gov/Survey-Analysis.

11. Arseneault, L., Walsh, E., Trzeniewski, K., Newcombe, R., \& Caspi A. (2006). Bullying victimization uniquely contributes to adjustment problems in young children: A nationally representative cohort study. Pediatrics, 118(1), 130-138.

12. Fowler, P. J., Tompsett, C. J., Braciszewski, J. M., Jacques-Tiura, A. J., Baltes, B. B. (2009). Community violence: A meta-analysis on the effect of exposure and mental health outcomes of children and adolescents. Development and Psychopathology, $21(1), 227-259$.

13. Jennings, W. G., Piquero, A. R., \& Reingle, J. M. (2012). On the overlap between victimization and offending: A review of the literature. Aggression and Violent Behavior, 17(1), 16-26.

14. Menard, S. (2002). Short- and long-term consequences of adolescent victimization. Youth Violence Research Bulletin. Washington, DC: U.S. Department of Justice, Office of Justice Programs, Office of Juvenile Justice and Delinquency Prevention. Retrieved from https://www.ncjrs.gov/pdffiles1/ojjdp/191210.pdf. 
15. National Task Force on Children Exposed to Violence, Listenbee, R. L., \& Torre, J. (2012). Report of the Attorney General's National Task Force on Children Exposed to Violence. Washington, DC: U.S. Department of Justice. Retrieved from https://www. justice.gov/defendingchildhood.

16. Miller, T. R., Fisher, D. A., \& Cohen, M. A. (2001). Costs of juvenile violence: Policy implications. Pediatrics, 107(1), 1-7.

17. Welsh, B. C., Loeber, R., Stevens, B. R., Stouthamer-Loeber, M., Cohen, M. A., \& Farrington, D. P. (2008). Costs of juvenile crime in urban areas: A longitudinal perspective. Youth Violence and Juvenile Justice, 6(1), 3-27.

18. Dahlberg, L. L., \& Simon, T. R. (2006). Predicting and preventing youth violence: Developmental pathways and risk. In J. R. Lutzker (Ed.), Preventing violence: Research and evidence-based intervention strategies (pp. 97-124). Washington, DC: American Psychological Association.

19. Herrenkohl, T. I., Maguin, E., Hill, K. G., Hawkins, J. D., Abbott, R. D., \& Catalano, R. F. (2000). Developmental risk factors for youth violence. Journal of Adolescent Health, 26(3), 176-186.

20. Thornberry, T. P., \& Krohn, M. D. (2006). Taking stock of delinquency: An overview of findings from contemporary longitudinal studies. New York, NY: Kluwer Academic Publishers.

21. World Health Organization. (2015). Preventing youth violence: An overview of the evidence. Geneva, Switzerland: World Health Organization. Retrieved from http://www.who.int/violence_injury_prevention/violence/youth/youth_violence/en/.

22. David-Ferdon, C., \& Simon, T. R. (2012). Striving To Reduce Youth Violence Everywhere (STRYVE): The Centers for Disease Control and Prevention's national initiative to prevent youth violence foundational resource. Atlanta, GA: Centers for Disease Control and Prevention. Retrieved from http://www.cdc.gov/violenceprevention/pdf/stryve_foundational_resource-a.pdf.

23. Abram, K. M., Teplin, L. A., Charles, D. R., Longworth, S. L., McClelland, G. M., \& Dulcan, M. K. (2004). Posttraumatic stress disorder and trauma in youth in juvenile detention. Archives of General Psychiatry, 61(4), 403-410.

24. Ferguson, C. J., San Miguel, C., \& Hartley, R. D. (2009). A multivariate analysis of youth violence and aggression: The influence of family, peers, depression, and media violence. The Journal of Pediatrics, 155(6), 904-908.

25. Foshee, V. A., Reyes, H. L. M., Ennett, S. T., Suchindran, C., Mathias, J. P., Karriker-Jaffe, K. J., ... Benefield, T. S. (2011). Risk and protective factors distinguishing profiles of adolescent peer and dating violence perpetration. Journal of Adolescent Health, 48(4), 344-350.

26. Hong, J. S., \& Espelage, D. L. (2012). A review of research on bullying and peer victimization in school: An ecological system analysis. Aggression and Violent Behavior, 17(4), 311-322.

27. Sprott, J. B., Doob, A. N., \& Jenkins, J. M. (2001). Problem behaviour and delinquency in children and youth. Canadian Centre for Justice Statistics. Retrieved from https://www.researchgate.net/profile/Jennifer_Jenkins3/publication/265157555_ PROBLEM_BEHAVIOUR_AND_DELINQUENCY_IN_CHILDREN_AND_YOUTH/links/54c7ae910cf238bb7d0b01f7.pdf.

28. Kirk, D. S., \& Sampson, R. J. (2013). Juvenile arrest and collateral educational damage in the transition to adulthood. Sociology of Education, 86(1), 36-62.

29. McGowan, A., Hahn, R., Liberman, A., Crosby, A., Fullilove, M., Johnson, R., ... Task Force on Community Preventive Services. (2007). Effects on violence of laws and policies facilitating the transfer of juveniles from the juvenile justice system to the adult justice system: A systematic review. American Journal of Preventive Medicine, 32(4), S7-S28.

30. Mendel, R. A. (2011). No place for kids: The case for reducing juvenile incarceration. Baltimore, MD: The Annie E. Casey Foundation. Retrieved from http://www.aecf.org/m/resourcedoc/aecf-NoPlaceForKidsFullReport-2011.pdf. 
31. American Psychological Association. (2013). Gun violence: Prediction, prevention, and policy. Washington, DC: American Psychological Association. Retrieved from http://www.apa.org/pubs/info/reports/gun-violence-report.pdf.

32. Hardy, M. S. (2006). Keeping children safe around guns: Pitfalls and promises. Aggression and Violent Behavior, 11(4), $352-366$.

33. Farrington, D. P., Loeber, R., \& Ttofi, M. M. (2012). Risk and protective factors for offending. In B. C. Welsh \& D. P. Farrington (Eds.), The Oxford handbook of crime prevention (pp. 46-69). New York, NY: Oxford University Press.

34. Malik, S., Sorenson, S. B., \& Aneshensel, C. S. (1997). Community and dating violence among adolescents: Perpetration and victimization. Journal of Adolescent Health, 21(5), 291-302.

35. Maguin, E., Hawkins, J. D., Catalano, R. F., Hill, K., Abbott, R., \& Herrenkohl, T. (1995, November). Risk factors measured at three ages for violence at age 17-18. Paper presented at the American Society of Criminology, Boston, MA.

36. Sampson, R., \& Lauritsen, J. (1994). Violent victimization and offending: Individual-, situational-, and community-level risk factors. In A. J. Reiss \& J. A. Roth (Eds.), Understanding and preventing violence vol. 3, social influences (pp. 1-144). Washington, DC: National Academy Press.

37. Toomey, T. L., Erickson, D. J., Carlin, B. P., Lenk, K. M., Quick, H. S., Jones, A. M., \& Harwood, E. M. (2012). The association between density of alcohol establishments and violent crime within urban neighborhoods. Alcoholism Clinical \& Experimental Research, 36(8), 1468-1473.

38. Sampson, R. J., Morenoff, J. D., \& Raudenbush, S. (2005). Social anatomy of racial and ethnic disparities in violence. American Journal of Public Health, 95(2), 224-232.

39. Sharkey, P. T., \& Sampson, R. J. (2015). Violence, cognition, and neighborhood inequality in America. In R. K. Schutt, L. J. Seidman, \& M. S. Keshavan (Eds.), Social neuroscience: Brain, mind, and society (pp. 320-329). Cambridge, MA: Harvard University Press.

40. Zimmerman, G. M., \& Messner, S. F. (2013). Individual, family background, and contextual explanations of racial and ethnic disparities in youths' exposure to violence. American Journal of Public Health, 103(3), 435-442.

41. Hall, J. E., Simon, T. R., Mercy, J. A., Loeber, R., Farrington, D. P., \& Lee, R. D. (2012). Centers for Disease Control and Prevention's expert panel on protective factors for youth violence perpetration: Background and overview. American Journal of Preventive Medicine, 43(2), S1-S7.

42. Kim, B. E., Gilman, A. B., Hill, K. G., \& Hawkins, J. D. (2016). Examining protective factors against violence among high-risk youth: Findings from the Seattle Social Development Project. Journal of Criminal Justice, 45, 19-25.

43. Ttofi, M. M., Farrington, D. P., Piquero, A. R., \& DeLisi, M. (2016). Protective factors against offending and violence: Results from prospective longitudinal studies. Journal of Criminal Justice, 45, 1-3.

44. Resnick, M. D., Ireland, M., \& Borowsky, I. (2004). Youth violence perpetration: What protects? What predicts? Findings from the National Longitudinal Study of Adolescent Health. Journal of Adolescent Health, 35(5), 424.e1-424.e10.

45. Stoddard, S. A., Whiteside, L., Zimmerman, M. A., Cunningham, R. M., Chermack, S. T., \& Walton, M. A. (2013). The relationship between cumulative risk and promotive factors and violent behavior among urban adolescents. American Journal of Community Psychology, 51(1-2), 57-65.

46. Bilukha, O., Hahn, R., Crosby, A., Fullilove, M., Liberman, A., Moscicki, E., ... Task Force on Community Preventive Services. (2005). The effectiveness of early childhood home visitation in preventing violence: A systematic review. American Journal of Preventive Medicine, 28(2S1), 11-39. 
47. Burrus, B., Leeks, K. D., Sipe, T. A., Dolina, S., Soler, R. E., Elder, E. W., ... Community Preventive Services Task Force. (2012). Person-to-person interventions targeted to parents and other caregivers to improve adolescent health: A community guide systematic review. American Journal of Preventive Medicine, 42(3), 316-326.

48. Derzon, J. H. (2010). The correspondence of family features with problem, aggressive, criminal, and violent behavior: A meta-analysis. Journal of Experimental Criminology, 6(3), 263-292.

49. Farrington, D. P., \& Welsh, B. C. (2003). Family-based prevention of offending: A meta-analysis. Australian \& New Zealand Journal of Criminology, 36(2), 127-151.

50. Mercy, J. A., \& Saul, J. (2009). Creating a healthier future through early interventions for children. Journal of the American Medical Association, 301(21), 262-264.

51. Piquero A. R., Farrington, D. P., Welsh, B. C., Tremblay, R., \& Jennings, W. G. (2009). Effects of family/parent training programs on antisocial behavior and delinquency. Journal of Experimental Criminology, 5(2), 83-120.

52. Piquero, A. R., Jennings, W. G., Diamond, B., Farrington, D. P., Tremblay, R. E., Welsh, B. C., \& Gonzalez, J, M. R. (2016). A metaanalysis update on the effects of early family/parent training programs on antisocial behavior and delinquency. Journal of Experimental Criminology, 12(2), 229-248.

53. DuBois, D. L., Portillo, N., Rhodes, J. E., Silverthorn, N., \& Valentine, C. (2011). How effective are mentoring programs for youth? A systematic assessment of the evidence. Psychological Science in the Public Interest, 312(2), 57-91.

54. Hurd, N. M., Zimmerman, M. A., \& Xue, Y. (2009). Negative adult influences and the protective effects of role models: A study with urban adolescents. Journal of Youth and Adolescence, 38(6), 777-789.

55. Riggs, N. R., \& Greenberg, M. T. (2004). After-school youth development programs: A developmental-ecological model of current research. Clinical Child and Family Review, 7(3), 177-190.

56. Crowe, T. D. (2000). Crime prevention through environmental design: Applications of architectural design and space management concepts. Boston, MA: Butterworth-Heinemann.

57. Lorenc, T., Petticrew, M., Whitehead, M., Neary, D., Clayton, S., Wright, K., ... Renton, A. (2013). Environmental interventions to reduce fear of crime: Systematic review of effectiveness. Systematic Reviews, 2(30), 1-10.

58. MacDonald, J. M., Stokes, R., \& Bluthenthal, R. (2010). The role of community context in business district revitalization strategies. Public Performance \& Management Review, 33(3), 436-458.

59. Ellen, I. G., O'Regan, K. M., \& Voicu, I. (2009). Siting, spillovers, and segregation: A reexamination of the Low Income Housing Tax Credit Program. In E. L. Glaeser, \& J. M. Quigley (Eds.), Housing Markets and the Economy: Risk, Regulation, and Policy (pp. 233-267). Cambridge, MA: Lincoln Institute of Land Policy.

60. Milam, A., J., Buggs, S. A., Debra, C., Furr-Holden, M., Leaf, P. J., Bradshaw, C. P., \& Webster, D. (2016). Changes in attitudes toward guns and shootings following Implementation of the Baltimore Safe Streets intervention. Journal of Urban Health, 93(4), 609-626.

61. Morenoff, J. D., Sampson, R. J., \& Raudenbush, S. W. (2001). Neighborhood inequality, collective efficacy, and the spatial dynamics of urban violence. Criminology, 39(3), 517-559.

62. Reese, L. R, Vera, E. M., Simon, T. R., \& Ikeda, R. M. (2000). The role of families and care givers as risk and protective factors in preventing youth violence. Clinical Child and Family Psychology Review, 3(1), 61-77. 
63. Sampson, R. J., Morenoff, J. D., \& Gannon-Rowley, T. (2002). Assessing "neighborhood effects": Social processes and new directions in research. Annual Review of Sociology, 28, 443-478.

64. Centers for Disease Control and Prevention. (2016). Preventing multiple forms of violence: A strategic vision for connecting the dots. Atlanta, GA: Division of Violence Prevention, National Center for Injury Prevention and Control, Centers for Disease Control and Prevention. Retrieved from http://www.cdc.gov/violenceprevention/pdf/strategic_vision.pdf.

65. Wilkins, N., Tsao, B., Hertz, M., Davis, R., \& Klevens, J. (2014). Connecting the dots: an overview of the links among multiple forms of violence. Atlanta, GA: National Center for Injury Prevention and Control, Centers for Disease Control and Prevention. Retrieved from http://www.cdc.gov/violenceprevention/pdf/connecting_the_dots-a.pdf.

66. Hamby, S., \& Grych, J. (2013). The web of violence: Exploring connections among different forms of interpersonal violence and abuse. In R. J. Johnson (Series Ed.), Books by Marquette University Faculty (pp. 1-106). New York, NY: Springer.

67. National Scientific Council on the Developing Child. (2005). Excessive stress disrupts the architecture of the developing brain. Working paper No. 3. Boston, MA: Center on the Developing Child at Harvard University. Retrieved from http:// developingchild.harvard.edu/resources/wp3/.

68. Shonkoff, J. P., \& Phillips, D. A. (Eds.). (2000). From neurons to neighborhoods: The science of early childhood development. National Research Council and Institute of Medicine. Washington DC: National Academy Press.

69. Hahm, H. C., Lee, Y., Ozonoff, A., \& Van Wert, M. J. (2010). The impact of multiple types of child maltreatment on subsequent risk behaviors among women during the transition from adolescence to young adulthood. Journal of Youth and Adolescence, 39(5), 528-540.

70. Espelage, D. L., Basile, K. C., \& Hamburger, M. E. (2012). Bullying perpetration and subsequent sexual violence perpetration among middle school students. Journal of Adolescent Health, 50(1), 60-65.

71. Foshee, V. A., Reyes, H. L. M., Vivolo-Kantor, A. M., Basile, K. C., Chang, L., Faris, R., \& Ennett, S. (2014). Bullying as a predictor of adolescent dating violence: A longitudinal assessment. Journal of Adolescent Health, 55(3), 439-444.

72. Hertz, M., Everett, S., Barrios, L., David-Ferdon, C., \& Holt, M. (2015). Association between bullying and health risk behaviors among high school students in the United States. Journal of School Health, 85(12), 833-842.

73. Klomek, A. B., Sourander, A., \& Gould, M. (2010).The association of suicide and bullying in childhood to young adulthood: A review of cross-sectional and longitudinal research findings. Canadian Journal of Psychiatry, 55(5), 282-288.

74. Nansel, T., Overpeck, M., Haynie, D., Ruan, W., \& Scheidt, P. (2003). Relationships between bullying and violence among U.S. youth. Archives of Pediatric \& Adolescent Medicine, 157(4), 348-353.

75. Centers for Disease Control and Prevention. (2016). The guide to community preventive services: The community guide. Atlanta, GA: Centers for Disease Control and Prevention, Office of Surveillance, Epidemiology, and Laboratory Services. Retrieved from http://www.thecommunityguide.org/index.html.

76. Center for the Study and Prevention of Violence. (2016). Blueprints for violence prevention. Boulder, CO: University of Colorado Boulder, Institute of Behavioral Science, Center for the Study and Prevention of Violence. Retrieved from http:// www.colorado.edu/cspv/blueprints/.

77. Matjasko, J. L., Vivolo-Kantor, A. M., Massetti, G. M., Holland, K. M., Holt, M. K., \& Cruz, J. D. (2012). A systematic meta-review of evaluations of youth violence prevention programs: Common and divergent findings from 25 years of meta-analyses and systematic reviews. Aggression and Violent Behavior, 17(6), 540-552. 
78. Cook, P., \& MacDonald, J. (2011). Public safety through private action: An economic assessment of BIDs. The Economics Journal, 121(552), 445-462.

79. Reynolds, A. J., Temple, J. A., White. B. A. B., Ou, S., \& Robertson, D. L. (2011). Age-26 cost-benefit analysis of the Child-Parent Early Education Program. Child Development, 82(1), 379-404.

80. Washington State Institute for Public Policy. (2016). Cost-benefits results. Olympia, WA: Washington State Institute for Public Policy. Retrieved from http://www.wsipp.wa.gov/BenefitCost.

81. Abt, T., \& Winship, C. (2016). What works in reducing community violence: A meta-review and field study for the northern triangle. Bethesda, MD: Democracy International, Inc. Retrieved from https://www.usaid.gov/sites/default/files/USAID-2016What-Works-in-Reducing-Community-Violence-Final-Report.pdf.

82. Heinze, J. E., Reischl, T. M., Bai, M., Roche, J. S., Morrel-Samuels, S., Cunningham, R. M., \& Zimmerman, M. A. (2016). A comprehensive prevention approach to reducing assault offenses and assault injuries among youth. Prevention Science, 17(2), 167-176.

83. Wilson, J. J., \& Howell, J. C. (1993). Comprehensive strategy for serious, chronic and violent juvenile offenders. Washington, DC: U.S. Department of Justice, Office of Juvenile Justice and Delinquency Prevention. Retrieved from https://www.ncjrs.gov/ pdffiles1/ojjdp/143453.pdf.

84. James-Burdumy, S., Dynarski, M., \& Deke, J. (2008). After-school program effects on behavior: Results from the 21st Century Community Learning Centers program national evaluation. Economic Inquiry, 46(1), 13-18.

85. James-Burdumy, S., Dynarski, M., \& Deke, J. (2007). When elementary schools stay open late: Results from the national evaluation of the 21st Century Community Learning Centers program. Educational Evaluation and Policy Analysis, 29(4), 296-318.

86. Mihalic, S., Huizinga, D., Ladika, A., Knight, K., \& Dyer, C. (2011). CasaStart final report. Boulder, CO: University of Colorado. Center for the Study and Prevention of Violence.

87. Petrosino, A., Turpin-Petrosino, C., Hollis-Peel, M. E., \& Lavenberg, J. G. (2013). Scared straight and other juvenile awareness programs for preventing juvenile delinquency: A systematic review. Campbell Systematic Reviews, 5, 1-55.

88. Institute of Medicine and National Research Council. (2013). Priorities for research to reduce the threat of firearm-related violence. Washington, DC: National Academy of Sciences. Retrieved from http://www.nationalacademies.org/hmd/ Reports/2013/Priorities-for-Research-to-Reduce-the-Threat-of-Firearm-Related-Violence.aspx.

89. Tolan, P. H., Henry, D. B., Schoeny, M. S., Lovegrove, P., \& Nichols, E. (2014). Mentoring programs to affect delinquency and associated outcomes of youth at risk: A comprehensive meta-analytic review. Journal of Experimental Criminology, 10(2), 179-206.

90. Centers for Disease Control and Prevention. (2015). CDC injury center research priorities. Atlanta, GA: Centers for Disease Control and Prevention, National Center for Injury Prevention and Control. Retrieved from http://www.cdc.gov/injury/pdfs/ researchpriorities/cdc-injury-research-priorities.pdf.

91. Massetti, G. M., Holland, K. M., \& Gorman-Smith, D. (2016). Implementation measurement for evidence-based violence prevention programs in communities. Journal of Community Health, 41(4), 881-894.

92. Wilson, S. J., Lipsey, M. W., \& Derzon, J. H. (2003). The effects of school-based intervention programs on aggressive behavior: A meta-analysis. Journal of Consulting and Clinical Psychology, 71(1), 136-149.

93. Mihalic, S. F., \& Elliott, D. S. (2015). Evidence-based programs registry: Blueprints for Healthy Youth Development. Evaluation and Program Planning, 48, 124-131. 
94. Pew Charitable Trusts (2012). Better programs, better results: rigorous quality assurance ensures that Washington state's evidencebased programs produce expected results. Washington, DC: Pew Center on the States and MacArthur Foundation. Retrieved from http://www.pewtrusts.org/en/research-and-analysis/issue-briefs/2012/07/26/better-programs-better-results.

95. Florence, C., Shepherd, J., Brennan, I., \& Simon, T. (2014). An economic evaluation of anonymized information sharing in a partnership between health services, police and local government for preventing violence-related injury. Injury Prevention, 20(2), 108-114.

96. Florence, C., Shepherd, J., Brennan, I., \& Simon, T. (2011). Effectiveness of anonymised information sharing and use in health service, police, and local government partnership for preventing violence related injury: Experimental study and time series analysis. British Medical Journal, 342, 1-9.

97. Hawkins, J. D., Catalano, R. F., Arthur, M. W., Egan, E., Brown, E. C., Abbott, R. D., \& Murray, D. M. (2008). Testing Communities That Care: The rationale, design and behavioral baseline equivalence of the community youth development study. Prevention Science, 9(3), 178-190.

98. Hawkins, J. D., Oesterle, S., Brown, E. C., Abbott, R. D., \& Catalano, R. (2014). Youth problem behaviors 8 years after implementing the Communities That Care prevention system: A community-randomized trial. JAMA Pediatrics, 168(2), 122-129.

99. Kuklinski, M., Briney, J., Hawkins, J., \& Catalano, R. (2011). Cost-benefit analysis of Communities That Care outcomes at eighth grade. Prevention Science, 13(2), 150-161.

100. Quigg, Z., Hughes, K., \& Bellis, M. A. (2012). Data sharing for prevention: A case study in the development of a comprehensive emergency department injury surveillance system and its use in preventing violence and alcohol-related harms. Injury Prevention, 18(5), 315-320.

101. Redmond, C., Spoth, R. L., Shin, C., Schainker, L. M., Greenberg, M. T., \& Feinberg, M. (2009). Long-term protective factor outcomes of evidence-based interventions implemented by community teams through a community-university partnership. Journal of Primary Prevention, 30(5), 513-530.

102. Spoth, R. L., Trudeau, L. S., Redmond, C. R., Shin, C., Greenberg, M. T., Feinberg, M. E., \& Hyun, G. (2015). PROSPER partnership delivery system: Effects on adolescent conduct problem behavior outcomes through 6.5 years past baseline. Journal of Adolescence, 45, 44-55.

103. Eckenrode, J., Campa, M., Luckey, D. W., Henderson, C. R., Cole, R. Kitzman, H., ... Olds, D. (2010). Long-term effects of prenatal and infancy nurse home visitation on the life course of youths: 19-year follow-up of a randomized trial. Archives of Pediatrics \& Adolescent Medicine, 164(1), 9-15.

104. Olds, D. L., Henderson, C. R., Cole, R., Eckenrode, J., Kitzman, H., Luckey, D., .. Powers, J. (1998). Long-term effects of nurse home visitation on children's criminal and antisocial behavior: 15-year follow-up of a randomized controlled trial. Journal of the American Medical Association, 280(14), 1238-1244.

105. Reynolds, A. J., Temple, J. A., Robertson, D. L., \& Mann, E. A. (2001). Long-term effects of an early childhood intervention on educational achievement and juvenile arrest: A 15-year follow-up of low-income children in public schools. Journal of the American Medical Association, 285(18), 2339-2346.

106. Basile, K. C., DeGue, S., Jones, K., Freire, K., Dills, J., Smith, S. G., \& Raiford, J. L. (2016). STOP SV: A technical package to prevent sexual violence. Atlanta, GA: National Center for Injury Prevention and Control, Centers for Disease Control and Prevention. Retrieved from http://www.cdc.gov/violenceprevention/pdf/sv-prevention-technical-package.pdf. 
107. Fortson, B. L., Klevens, J., Merrick, M. T., Gilbert, L. K., \& Alexander, S. P. (2016). Preventing child abuse and neglect: A technical package for policy, norm, and programmatic activities. Atlanta, GA: National Center for Injury Prevention and Control, Centers for Disease Control and Prevention. Retrieved from http://www.cdc.gov/violenceprevention/pdf/can-prevention-technicalpackage.pdf.

108. Niolon, P. H., Kearns, M., Dills, J., Rambo, K., Irving, S., Armstead, T., \& Gilbert, L. (forthcoming 2017). Eliminating intimate partner violence across the lifespan: A technical package to prevent intimate partner violence, including teen dating violence. Atlanta, GA: National Center for Injury Prevention and Control, Centers for Disease Control and Prevention.

109. Stone, D. M., Holland, K. M., Bartholow, B., Crosby, A. E., Davis, S., \& Wilkins, N. (forthcoming 2017). Preventing suicide: A technical package of policy, programs, and practices. Atlanta, GA: National Center for Injury Prevention and Control, Centers for Disease Control and Prevention.

110. DeVore, E. R., \& Ginsburg, K. R. (2005). The protective effects of good parenting on adolescents. Current Opinion in Pediatrics, $17(4), 460-465$.

111. National Scientific Council on the Developing Child. (2004). Young children develop in an environment of relationships. Working paper No.1. Boston, MA: Center on the Developing Child at Harvard University. Retrieved from http://developingchild.harvard. edu/wp-content/uploads/2004/04/Young-Children-Develop-in-an-Environment-of-Relationships.pdf.

112. Hawkins, J. D., Herrenkohl, T. I., Farrington, D. P., Brewer, D., Catalano, R. F., Harachi, T. W., \& Cothern, L. (2000). Predictors of youth violence. Washington, DC: U.S. Department of Justice, Office of Justice Programs, Office of Juvenile Justice and Delinquency Prevention. Retrieved from https://www.ncjrs.gov/html/ojjdp/jjbul2000_04_5/contents.html.

113. Hoeve, M., Dubas, J. S., Eichelsheim, V. I., Van der Laan, P. H., Smeenk, W., \& Gerris, J. R. (2009). The relationship between parenting and delinquency: A meta-analysis. Journal of Abnormal Child Psychology, 37(6), 749-775.

114. Avellar, S., Paulsell, D., Sama-Miller, E., Del Grosso, P., Akers, L., \& Kleinman, R. (2016). Home visiting evidence of effectiveness review: Executive summary. Office of Planning, Research and Evaluation, Administration for Children and Families, U.S. Department of Health and Human Services. Washington, DC. Retrieved from http://homvee.acf.hhs.gov/.

115. Lundahl, B., Risser, H. J., \& Lovejoy, M. C. (2006). A meta-analysis of parent training: Moderators and follow-up effects. Clinical Psychology Review, 26(1), 86-104.

116. O'Brien, M., \& Daley, D. (2011). Self-help parenting interventions for childhood behaviour disorders: A review of the evidence. Child: Care, Health and Development, 37(5), 623-637.

117. Sweet, M. A., \& Appelbaum, M. I. (2004). Is home visiting an effective strategy? A meta-analytic review of home visiting programs for families with young children. Child Development, 75(5), 1435-1456.

118. Olds, D. L., Henderson, C. R., \& Kitzman, H. (1994). Does prenatal and infancy nurse home visitation have enduring effects on qualities of parental caregiving and child health at 25 to 50 months of life? Pediatrics, 93(1), 89-98.

119. Olds, D. L., Eckenrode, J., Henderson, C. R., Kitzman, H., Powers, J., Cole, R., ... Luckey, D. (1997). Long-term effects of home visitation on maternal life course and child abuse and neglect: Fifteen-year follow-up of a randomized trial. Journal of the American Medical Association, 278(8), 637-643.

120. Menting, A. T., de Castro, B. O., \& Matthys, W. (2013). Effectiveness of the Incredible Years parent training to modify disruptive and prosocial child behavior: A meta-analytic review. Clinical Psychology Review, 33(8), 901-913.

121. Webster-Stratton, C. (2016). The Incredible Years ${ }^{\circledR}$ series: A developmental approach. In M. J. Van Ryzin, K. L. Kumpfer, G. M. Fosco, \& M. T. Greenberg (Eds.), Family-based prevention programs for children and adolescents: Theory, research, and largescale dissemination (pp. 42-67). New York, NY: Psychology Press. 
122. Bank, L., Marlowe, J. H., Reid, J. B., Patterson, G. R., \& Weinrott, M. R. (1991). A comparative evaluation of parent-training interventions for families of chronic delinquents. Journal of Abnormal Child Psychology, 19(1), 15-33.

123. Forgatch, M. S., Patterson, G. R., DeGarmo, D. S., \& Beldavs, Z. (2009). Testing the Oregon delinquency model with nine-year follow-up of the Oregon Divorce Study. Development and Psychopathology, 21(5), 637-660.

124. Patterson, G. R., Forgatch, M. S., \& DeGarmo, D. S. (2010). Cascading effects following intervention. Development and Psychopathology, 22(4), 949-970.

125. Wachlarowicz, M., Snyder, J., Low, S., Forgatch, M. S., \& DeGarmo, D. A. (2012). The moderating effects of parent antisocial characteristics on the effects of Parent Management Training - Oregon (PMTO). Prevention Science, 13(3), 229-240.

126. Spoth, R. L., Redmond, C., \& Shin, C. (2000). Reducing adolescents' aggressive and hostile behaviors: Randomized trial effects of a brief family intervention 4 years past baseline. Archives of Pediatrics \& Adolescent Medicine, 154(12), 1248-1257.

127. Spoth, R., Redmond, C., \& Lepper, H. (1999). Alcohol initiation outcomes of universal family focused preventive interventions: One-and two-year follow-ups of a controlled study. Journal of Studies on Alcohol, 13, 103-110.

128. Spoth, R., Redmond, C., \& Shin, C. (1998). Direct and indirect latent-variable parenting outcomes of two universal familyfocused preventive interventions: Extending a public health-oriented research base. Journal of Consulting \& Clinical Psychology, 66(2), 385-399.

129. Spoth, R. L., Redmond, C., \& Shin, C. (2001). Randomized trial of brief family interventions for general populations: Adolescent substance use outcomes 4 years following baseline. Journal of Consulting \& Clinical Psychology, 69(4), 627-642.

130. Lochman, J.E., \& Wells, K.C. (2004). The Coping Power program for preadolescent aggressive boys and their parents: Outcome effects at the one-year follow-up. Journal of Consulting \& Clinical Psychology, 72(4), 571-578.

131. Lochman, J. E., \& Wells, K. C. (2003). Effectiveness of the Coping Power Program and of classroom intervention with aggressive children: Outcomes at a one-year follow-up. Behavior Therapy, 34(4), 493-515.

132. Lochman, J. E., Wells, K. C., Qu, L., \& Chen, L. (2013). Three year follow-up of Coping Power intervention effects: Evidence of neighborhood moderation? Prevention Science, 14(4), 364-376.

133. Pantin, H., Coatsworth, J. D., Feaster, D. J., Newman, F. L., Briones, E., Prado, G., ... Szapocznik, J. (2003). Familias Unidas: The efficacy of an intervention to promote parental investment in Hispanic immigrant families. Prevention Science, 4(3), 189-201.

134. Pantin, H., Prado, G., Lopez, B., Huang, S., Tapia, M., Schwartz, S., ... Branchini, J. (2009). A randomized controlled trial of Familias Unidas for Hispanic adolescents with behavior problems. Psychosomatic Medicine, 71(9), 987-995.

135. Prado, G., Cordova, D., Huang, S., Estrada, Y., Rosen, A., Bacio, G. A., ... McCollister, K. (2012). The efficacy of Familias Unidas on drug and alcohol outcomes for Hispanic delinquent youth: Main effects and interaction effects by parental stress and social support. Drug and Alcohol Dependence, 125, S18-S25.

136. Braveman, P., \& Gottlieb, L. (2014). The social determinants of health: It's time to consider the causes of the causes. Public Health Reports, 129(suppl 2), 19-31.

137. Manning, M., Homel, R., \& Smith, C. (2010). A meta-analysis of the effects of early developmental prevention programs in atrisk populations on non-health outcomes in adolescence. Children and Youth Services Review, 32(4), 506-519.

138. Hawkins, J. D., Catalano, R. F., Kosterman, R., Abbott, R., \& Hill, K. G. (1999). Preventing adolescent health-risk behaviors by strengthening protection during childhood. Archives of Pediatrics \& Adolescent Medicine, 153(3), 226-234. 
139. Mersky, J. P., Topitzes, J. D., \& Reynolds, S. W. (2011). Maltreatment prevention through early childhood intervention: A confirmatory evaluation of the Chicago child-parent center preschool program. Children \& Youth Services Review, 33(8), 1454-1463.

140. Higgins, S., \& Katsipataki, M. (2015). Evidence from meta-analysis about parental involvement in education which supports their children's learning. Journal of Children's Services, 10(3), 280-290.

141. Reynolds, A. J., \& Robertson, D. L. (2003). School-based early intervention and later child maltreatment in the Chicago Longitudinal Study. Child Development, 74(1), 3-26.

142. Chicago Public Schools. (2014). Child Parent Center. Retrieved from http://cps.edu/Schools/EarlyChildhood/Pages/ Childparentcenter.aspx.

143. Reynolds, A. J., Temple, J. A., Ou, S. R., Robertson, D. L., Mersky, J. P., Topitzes, J. W., \& Niles, M. D. (2007). Effects of a schoolbased, early childhood intervention on adult health and well-being: A 19-year follow-up of low-income families. Archives of Pediatrics and Adolescent Medicine, 161(8), 730-739.

144. Love, J. M., Kisker, E. E., Ross, C., Constantine, J., Boller, K., Brooks-Gunn, J., ... Vogel, C. (2005). The effectiveness of Early Head Start for 3-year-old children and their parents: Lessons for policy and programs. Developmental Psychology, 41(6), 885-901.

145. Green, B. L., Ayoub, C., Bartlett, J. D., Von Ende, A., Furrer, C., Chazan-Cohen, R., ... Klevens, J. (2014). The effect of Early Head Start on child welfare system involvement: A first look at longitudinal child maltreatment outcomes. Children and Youth Services Review, 42, 127-135.

146. Harden, B. J., Chazan-Cohen, R., Raikes, H., \& Vogel, C. (2012). Early Head Start home visitation: The role of implementation in bolstering program benefits. Journal of Community Psychology, 40(4), 438-455.

147. Catalano, R. F., Berglund, M. L., Ryan, J. A., Lonczak, H. S., \& Hawkins, J. D. (2004). Positive youth development in the United States: Research findings on evaluations of positive youth development programs. The Annals of the American Academy of Political and Social Science, 591(1), 98-124.

148. Dahlberg, L. L. (1998). Youth violence in the United States: Major trends, risk factors, and prevention approaches. American Journal of Preventive Medicine, 14(4), 259-272.

149. Sullivan, T. N., Farrell, A. D., Bettencourt, A. F., \& Helms, S. W. (2008). Core competencies and the prevention of youth violence. New Directions for Child and Adolescent Development, 2008(122), 33-46.

150. Durlak, J. A., Weissberg, R. P., Dymnicki, A. B., Taylor, R. D., \& Schellinger, K. B. (2011). The impact of enhancing students' social and emotional learning: A meta-analysis of school-based universal interventions. Child Development, 82(1), 405-432.

151. Hahn, R., Fuqua-Whitley, D., Wethington, H., Lowy, J., Crosby, A., Fullilove, M., ... Task Force on Community Preventive Services. (2007). Effectiveness of universal school-based programs to prevent violent and aggressive behavior: A systematic review. American Journal of Preventive Medicine, 33(2), S114-S129.

152. Payton, J., Weissberg, R. P., Durlak, J. A., Dymnicki, A. B., Taylor, R. D., Schellinger, K. B., \& Pachan, M. (2008). The Positive impact of social and emotional learning for kindergarten to eighth-grade students: Findings from three scientific reviews. Chicago, IL: Collaborative for Academic, Social, and Emotional Learning. Retrieved from http://files.eric.ed.gov/fulltext/ED505370.pdf.

153. Lewis, K. M., Bavarian, N., Snyder, F. J., Acock, A., Day, J., DuBois, D. L., Ji, P., Schure, M. B., Silverthorn, N., Vuchinich, S., \& Flay, B. R. (2012). Direct and mediated effects of a social-emotional and character development program on adolescent substance use. The International Journal of Emotional Education, 4(1), 56-78.

154. Polanin, J. R., Espelage, D. L., \& Pigott, T. D. (2012). A meta-analysis of school-based bullying prevention programs' effects on bystander intervention behavior. School Psychology Review, 41(1), 47-65. 
155. Ttofi, M. M., \& Farrington, D. P. (2011). Effectiveness of school-based programs to reduce bullying: A systematic and metaanalytic review. Journal of Experimental Criminology, 7(1), 27-56.

156. Dolan, L. J., Kellam, S. G., Brown, C. H., Werthamer-Larsson, L., Rebok, G. W., Mayer, L. S., ... Wheeler, L. T. (1993). The shortterm impact of two classroom-based preventive interventions on aggressive and shy behaviors and poor achievement. Journal of Applied Developmental Psychology, 14(3), 317-345.

157. Kellam, S. G., Brown, C. H., Poduska, J. M., lalongo, N. S., Wang, W., Toyinbo, P., ... Wilcox, H. C. (2008). Effects of a universal classroom behavior management program in first and second grades on young adult behavioral, psychiatric, and social outcomes. Drug and Alcohol Dependence, 95(1), S5-S28.

158. Kellam, S. G., Rebok, G. W., lalongo, N., \& Mayer, L. S. (1994). The course and malleability of aggressive behavior from early first grade into middle school: Results of a developmental epidemiologically-based preventive trial. Journal of Child Psychology and Psychiatry 35(2), 259-282.

159. Petras, H., Kellam, S. G., Brown, C. H., Muthen, B. O., lalongo, N. S., \& Poduska, J. M. (2008). Developmental epidemiological courses leading to antisocial personality disorder and violent criminal behavior: Effects by young adulthood of a universal preventive intervention in first- and second-grade classrooms. Drug and Alcohol Dependence, 95(Suppl 1), 45-59.

160. Wilcox, H. C., Kellam, S. G., Brown, C. H., Poduska, J. M., lallongo, N. S., Wang, W., \& Anthony, J. C. (2008). The impact of two universal randomized first- and second-grade classroom interventions on young adult suicide ideation and attempts. Drug and Alcohol Dependence, 95(Suppl. 1), S60-S73.

161. Greenberg, M.T. \& Kusché, C.A. (2006). Building social and emotional competence: The PATHS curriculum. In S. R. Jimerson \& M. Furlong (Eds.), Handbook of school violence and school safety: From research to practice (pp. 395-412). Mahwah, NJ: Lawrence Erlbaum Associates Publishers.

162. Crean, H. F., \& Johnson, D. B. (2013). Promoting Alternative THinking Strategies (PATHS) and elementary school aged children's aggression: Results from a cluster randomized trial. American Journal of Community Psychology, 52(1-2), 56-72.

163. Schonfeld, D. J., Adams, R. E., Fredstrom, B. K., Weissberg, R. P., Gilman, R., Voyce, C., ... Speese-Linehan, D. (2015). Clusterrandomized trial demonstrating impact on academic achievement of elementary social-emotional learning. School Psychology Quarterly, 30(3), 406-420.

164. Botvin, G. J., Griffin, K. W., \& Nichols, T. D. (2006). Preventing youth violence and delinquency through a universal schoolbased prevention approach. Prevention Science, 7(4), 403-408.

165. Frey, K. S., Hirschstein, M., Edstrom, L., \& Snell, J. (2009). Observed reductions in school bullying, nonbullying aggression, and destructive bystander behavior: A longitudinal evaluation. Journal of Educational Psychology, 101(2), 466-481.

166. Brown, E. C., Low, S., Smith, B. H., \& Haggerty, K. P. (2011). Outcomes from a school-randomized control trial of Steps to Respect. School Psychology Review, 40(3), 423-443.

167. Lösel, F., \& Farrington, D. P. (2012). Direct protective and buffering protective factors in the development of youth violence. American Journal of Preventive Medicine, 43(2), S8-S23.

168. DuBois, D. L., \& Karcher, M. J. (Eds.). (2014). Handbook of youth mentoring. Second edition. Thousand Oaks, CA: Sage Publications.

169. Jolliffe, D., \& Farrington, D. P. (2007). A rapid evidence assessment of the impact of mentoring on re-offending: A summary. London: Home Office. Retrieved from http://www.youthmentoring.org.nz/content/docs/Home_Office_Impact_of_ mentoring.pdf. 
170. Sickmund, M., \& Puzzanchera, C. (Eds.). (2014). Juvenile offenders and victims: 2014 national report. Pittsburgh, PA: National Center for Juvenile Justice. Retrieved from http://www.ojjdp.gov/ojstatbb/nr2014/.

171. Durlak, J. A., Weissberg, R. P., \& Pachan, M. (2010). A meta-analysis of after-school programs that seek to promote personal and social skills in children and adolescents. American Journal of Community Psychology, 45(3-4), 294-309.

172. Gottfredson, D. C., Cross, A., \& Soulé, D. A. (2007). Distinguishing characteristics of effective and ineffective afterschool programs to prevent delinquency and victimization. Criminology \& Public Policy, 6(2), 601-631.

173. Big Brothers Big Sisters of America. (2016). 110 years of history. Tampa, FL: Big Brothers Big Sisters of America. Retrieved from http://www.bbbs.org/site/c.9ilLI3NGKhK6F/b.5960955/k.E56C/Starting_something_since_1904.htm.

174. Grossman, J. B., \& Tierney, J. P. (1998). Does mentoring work? An impact study of the Big Brothers Big Sisters program. Evaluation Review, 22(3), 403-426.

175. Herrera, C., Grossman, J. B., Kauh, T. J., \& McMaken, J. (2011). Mentoring in schools: An impact study of Big Brothers Big Sisters school-based mentoring. Child Development, 82(1), 346-361.

176. Chan C. S., Rhodes, J. E., Howard W. J., Lowe, S. R., Schwartz, S. E. O., \& Herrera C. (2013). Pathways of influence in schoolbased mentoring: The mediating role of parent and teacher relationships. Journal of School Psychology, 51(1), 129-142.

177. Roth, J. L., Malone, L. M., \& Brooks-Gunn, J. (2010). Does the amount of participation in afterschool programs relate to developmental outcomes? A review of the literature. American Journal of Community Psychology, 45(3-4), 310-324.

178. Goldschmidt, P., Huang, D., \& Chinen, M. (2007). The long-term effects of after-school programming on educational adjustment and juvenile crime: A study of the LA's BEST after-school program. Los Angeles, CA: National Center for Research on Evaluation, Standards, and Student Testing and University of California Los Angeles. Retrieved from http://www.chapinhall.org/ research/brief/after-school-programs-and-academic-impact.

179. After School Matters. (2016). Program information and requirements. Chicago, IL: After School Matters. Retrieved from http://www.afterschoolmatters.org/teens/programs/.

180. Goerge, R. M., Cusick, G. R., Wasserman, M., \& Gladden, R. M. (2007). After-school programs and academic impact: A study of Chicago's After School Matters. Chicago, IL: Chapin Hall, University of Chicago. Retrieved from http://www.chapinhall.org/ sites/default/files/publications/ChapinHallDocument(2)_0.pdf.

181. Hirsch, B. J., Hedges, L. V., Stawicki, J. A., \& Mekinda, M. A. (2011). After-school programs for high school students: an evaluation of After School Matters. Technical report. Evanston, IL: Northwestern University. Retrieved from http://www.sesp. northwestern.edu/docs/publications/1070224029553e7f678c09f.pdf.

182. Webster, D. W., Whitehill, J. M., Vernick, J. S., \& Curriero, F. C. (2013). Effects of Baltimore's Safe Streets program on gun violence: A replication of Chicago's CeaseFire program. Journal of Urban Health, 90(1), 27-40.

183. Butts, J. A., Roman, C. G., Bostwick, L., \& Porter, J. R. (2015). Cure violence: A public health model to reduce gun violence. Annual Review of Public Health, 36, 39-53.

184. Astor, R. A., Meyer, H. A., \& Behre, W. J. (1999). Unowned places and times: Maps and interviews about violence in high schools. American Educational Research Journal, 36(1), 3-42.

185. Bradshaw, C. P., Milam, A. J., Furr-Holden, C. D. M., \& Lindstrom Johnson, S. (2015). The School Assessment for Environmental Typology (SAfETy): An observational measure of the school environment. American Journal of Community Psychology, 56(34), 280-292. 
186. Johnson, S. L. (2009). Improving the school environment to reduce school violence: A review of the literature. Journal of School Health, 79(10), 451-465.

187. Wilcox, P., Augustine, M. C., \& Clayton, R. R. (2006). Physical environment and crime and misconduct in Kentucky schools. Journal of Primary Prevention, 27(3), 293-313.

188. Livingston, M., Livingston, M., Chikritzhs, T., \& Room, R. (2007). Changing the density of alcohol outlets to reduce alcoholrelated problems. Drug and Alcohol Review, 26(5), 557-566.

189. Massetti, G. M., \& David-Ferdon, C. (2016). Preventing violence among high-risk youth and communities with economic, policy, and structural strategies. Morbidity and Mortality Weekly Report, 65(1), 57-60.

190. MacDonald, J. M., Golinelli, D., Stokes, R. J., \& Bluthenthal, R. (2010). The effect of business improvement districts on the incidence of violent crime. Injury Prevention, 16(5), 327-332.

191. Casteel, C., \& Peek-Asa, C. (2000). Effectiveness of crime prevention through environmental design (CPTED) in reducing robberies. American Journal of Preventive Medicine, 18(4S), 99-115.

192. Bogar, S., \& Beyer, K. M. (2015). Green space, violence, and crime: A systematic review. Trauma, Violence, \& Abuse, 17(2), 160171.

193. Branas, C. C., Cheney, R. A., MacDonald, J. M., Tam, V. W., Jackson, T. D., \& Ten Have, T. R. (2011). A difference-in-difference analysis of health, safety, and greening vacant urban space. American Journal of Epidemiology, 174(11), 1296-1306.

194. Branas, C. C., Kondo, M. C., Murphy, S. M., South, E. C., Polsky, D., \& MacDonald, J. M. (2016). Urban blight remediation as a cost-beneficial solution to firearm violence. American Journal of Public Health. doi: 10.2105/AJPH.2016.303434.

195. Culyba, A. J., Jacoby, S. F., Richmond, T. S., Fein, J. A., Hohl, B. C., \& Branas, C. C. (2016). Modifiable neighborhood features associated with adolescent homicide. JAMA Pediatrics, 170(5), 473-480.

196. Donnelly, P., \& Kimble, C. E. (1997). Community organizing, environmental change, and neighborhood crime. Crime and Delinquency, 43(4), 493-511.

197. Welsh, B., \& Farrington, D. (2008). Effects of improved street lighting on crime: A systematic review. Campbell Systematic Reviews, 4(13), 1-61.

198. Center on Budget and Policy Priorities. (2016). Policy basics: The Earned Income Tax Credit. Washington, DC: Center on Budget and Policy Priorities. Retrieved from http://www.cbpp.org/research/federal-tax/policy-basics-the-earned-income-tax-credit.

199. Levitie, J., \& Koulish, J. (2008). State earned income tax credits: 2008 legislative update. Washington, DC: Center on Budget and Policy Priorities. Retrieved from http://www.cbpp.org/cms/?fa=view\&id=462.

200. Waldfogel, J. (2004). Welfare reform and the child welfare system. Children and Youth Services Review, 26(10), 919-929.

201. Pressman, S. (2011). Policies to reduce child poverty: Child allowances versus tax exemptions for children. Journal of Economic Issues, 45(2), 323-332.

202. Freedman, M., \& Owens, E. G. (2011). Low income housing development and crime. Journal of Urban Economics, 70(2-3), 115-131.

203. Anderson, P., Chisholm, D., \& Fuhr, D. C. (2009). Effectiveness and cost-effectiveness of policies and programmes to reduce the harm caused by alcohol. Lancet, 373(9682), 2234-2246. 
204. Community Preventive Services Task Force. (2016). Preventing excessive alcohol consumption. Atlanta, GA: Centers for Disease Control and Prevention, Office of Surveillance, Epidemiology, and Laboratory Services. Retrieved from http://www. thecommunityguide.org/alcohol/index.html.

205. Hahn, R. A., Middleton, J. C., Elder, R., Brewer, R., Fielding, J., Naimi, T. S., .. Community Preventive Services Task Force. (2012). Effects of alcohol retail privatization on excessive alcohol consumption and related harms: A Community Guide systematic review. American Journal of Preventive Medicine, 42(4), 418-427.

206. Masho, S. W., Bishop, D. L., Edmonds, T., \& Farrell, A. D. (2014). Using surveillance data to inform community action: The effect of alcohol sale restrictions on intentional injury-related ambulance pickups. Prevention Science, 15(1), 22-30.

207. Duailibi, S., Ponicki, W., Grube, J., Pinsky, I., Laranjeira, R., \& Raw, M. (2007). The effect of restricting opening hours on alcoholrelated violence. American Journal of Public Health, 97(12), 2276-2280.

208. Menéndez, P., Tusell, F., \& Weatherburn, D. (2015). The effects of liquor licensing restriction on alcohol-related violence in NSW, 2008-13. Addiction, 110(10), 1574-1582.

209. Wallin, E., Norstrom, T., \& Andreasson, S. (2003). Alcohol prevention targeting licensed premises: A study of effects on violence. Journal of the Studies on Alcohol, 64(2), 270-277.

210. Skogan, W. G., Hartnett, S. M., Bump, N., \& Dubois J. (2008). Evaluation of CeaseFire -Chicago. Evanston, IL: Northwestern University. Retrieved from http://www.skogan.org/files/Evaluation_of_CeaseFire-Chicago_Main_Report.03-2009.pdf.

211. Webster, D. W., Whitehill, J. M., Vernick, J. S., \& Parker, E. M. (2012). Evaluation of Baltimore's Safe Streets Program: Effects on attitudes, participants' experiences, and gun violence. Baltimore, MD: Johns Hopkins Center for the Prevention of Youth Violence, Johns Hopkins Bloomberg School of Public Health. Retrieved from: http://www.jhsph.edu/news/newsreleases/2012/_pdfs/Safe\%20Streets\%20evaluation\%20final.pdf.

212. Eron, L. D., \& Huesmann, L. R. (1990). The stability of aggressive behavior-even unto the third generation. In M. Lewis \& S. M. Miller (Eds.), Handbook of developmental psychopathology (pp. 147-156). New York, NY: Springer.

213. Moffitt, T. E., Caspi, A., Harrington, H., \& Milne, B. J. (2002). Males on the life-course-persistent and adolescent-limited antisocial pathways: Follow-up at age 26 years. Development and Psychopathology, 14(1), 179-207.

214. Tolan, P. H., Gorman-Smith, D., \& Loeber, R. (2000). Developmental timing of onsets of disruptive behaviors and later delinquency of inner-city youth. Journal of Child and Family Studies, 9(2), 203-220.

215. Gorman-Smith, D., \& Tolan, P. (1998). The role of exposure to community violence and developmental problems among inner-city youth. Developmental Psychopathology, 10(1), 101-116.

216. Abram, K. M., Washburn, J. J., Teplin, L. A., Emanuel, K. M., Romero, E. G., \& McClelland, G. M. (2007). Posttraumatic stress disorder and psychiatric comorbidity among detained youths. Psychiatric Services, 58(10), 1311-1316.

217. Buka, S. L., Stichick, T. L., Birdthistle, I., \& Earls, F. J. (2001). Youth exposure to violence: Prevalence, risks, and consequences. American Journal of Orthopsychiatry, 71(3), 298-310.

218. Farrington, D. P., Loeber, R., \& Howell, J. C. (2012). Young adult offenders: The need for more effective legislative options and justice processing. Criminology \& Public Policy, 11(4), 729-750.

219. Furlong, M., McGilloway, S., Bywater, T., Hutchings, J., Smith, S. M., \& Donnelly, M. (2013). Cochrane review: Behavioural and cognitive-behavioural group-based parenting programmes for early-onset conduct problems in children aged 3 to 12 years. Evidence-Based Child Health: A Cochrane Review Journal, 8(2), 318-692. 
220. Lipsey, M. W., Wilson, D. B., \& Cothern, L. (2000). Effective intervention for serious juvenile offenders. Washington, DC: U.S. Department of Justice, Office of Justice Programs, Office of Juvenile Justice and Delinquency Prevention. Retrieved from https://www.ncjrs.gov/pdffiles1/ojjdp/181201.pdf.

221. Cary, C. E., \& McMillen, J. C. (2012). The data behind the dissemination: A systematic review of trauma-focused cognitive behavioral therapy for use with children and youth. Children and Youth Services Review, 34(4), 748-757.

222. Child Welfare Information Gateway. (2012). Trauma-focused cognitive behavioral therapy for children affected by sexual abuse or trauma. Washington, DC: U.S. Department of Health and Human Services, Children's Bureau. Retrieved from https://www. childwelfare.gov/pubPDFs/trauma.pdf.

223. Cohen, J. A., Mannarino, A. P., Berliner, L., \& Deblinger, E. (2000). Trauma-focused cognitive behavioral therapy for children and adolescents: An empirical update. Journal of Interpersonal Violence, 15(11), 1202-1223.

224. Ko, S. J., Ford, J. D., Kassam-Adams, N., Berkowitz, S. J., Wilson, C., Wong, M., ... Layne, C. M. (2008). Creating trauma-informed systems: child welfare, education, first responders, health care, juvenile justice. Professional Psychology: Research and Practice, 39(4), 396-404.

225. Purtle, J., Corbin, T. J., Rich, L. J., \& Rich, J. A. (2015). Hospitals as a locus for violence intervention. In P. D. Donnelly \& C. L. Ward (Eds.), Oxford textbook of violence prevention: epidemiology, evidence, and policy (pp. 231-238). Oxford, United Kingdom: Oxford University Press.

226. Neville, F. G., Goodall, C. A., Williams, D. J., \& Donnelly, P. D. (2014). Violence brief interventions: A rapid review. Aggression and Violent Behavior, 19(6), 692-698.

227. de Arellano, M. A., R. Lyman, D. R., Jobe-Shields, L., George, P., Dougherty, R. H., Daniels, A. S., ... Delphin-Rittmon, M. E. (2014). Trauma-focused cognitive behavioral therapy: Assessing the evidence. Psychiatric Services, 65(5), 591-602.

228. Cohen, J. A., Mannarino, A. P., \& lyengar, S. (2011). Community treatment of posttraumatic stress disorder for children exposed to intimate partner violence. Archives of Pediatrics \& Adolescent Medicine, 165(1), 16-21.

229. Dorsey, S., Briggs, E. C., \& Woods, B. A. (2011). Cognitive-behavioral treatment for posttraumatic stress disorder in children and adolescents. Child and Adolescent Psychiatric Clinics of North America, 20(2), 255-269.

230. Stein, B. D., Jaycox, L. H., Kataoka, S. H., Wong, M., Tu, W., Elliott, M. N., \& Fink, A. (2003). A mental health intervention for schoolchildren exposed to violence: A randomized controlled trial. Journal of the American Medical Association, 290(5), 603611.

231. Gordon, D. A., Arbuthnot, J., Gustafson, K. E., \& McGreen, P. (1988). Home-based behavioral-systems family therapy with disadvantaged juvenile delinquents. American Journal of Family Therapy, 16(3), 243-255.

232. Gordon, D. A., Graves, K., \& Arbuthnot, J. (1995). The effect of Functional Family Therapy for delinquents on adult criminal behavior. Criminal Justice and Behavior, 22(1), 60-73.

233. Barton, C., Alexander, J. F., Waldron, H., Turner, C. W., \& Warburton, J. (1985). Generalizing treatment effects of Functional Family Therapy: Three replications. American Journal of Family Therapy, 13(3), 16-26.

234. Hartnett, D., Carr, A., \& Sexton, T. (2015). The effectiveness of Functional Family Therapy in reducing adolescent mental health risk and family adjustment difficulties in an Irish context. Family Process, 56(2), 287-304.

235. Waldron, H. B., Slesnick, N., Brody, J. L., Turner, C. W., \& Peterson, T. R. (2001). Treatment outcomes for adolescent substance abuse at 4- and 7-month assessments. Journal of Consulting and Clinical Psychology, 69(5), 802-813. 
236. Task Force on Community Preventive Services (2005). Recommendations to reduce violence through early childhood home visitation, therapeutic foster care, and firearm laws. American Journal of Preventative Medicine, 28(251), 6-10.

237. Eddy J. M., Whaley, R. B., \& Chamberlain, P. (2004). The prevention of violent behavior by chronic and serious male juvenile offenders: A two-year follow-up of a randomized clinical trial. Journal of Emotional and Behavioral Disorders, 12(1), 2-8.

238. Fisher, P. A., \& Gilliam, K. S. (2012). Multidimensional treatment foster care: An alternative to residential treatment for high risk children and adolescents. Psychosocial Intervention, 21(2), 195-203.

239. Smith, D. K., Chamberlain, P., \& Eddy, J. M. (2010). Preliminary support for multidimensional treatment foster care in reducing substance use in delinquent boys. Journal of Child \& Adolescent Substance Abuse, 19(4), 343-358.

240. Multisystemic Therapy Services. (2016). Multisystemic Therapy (MST) research at a glance: Published MST outcome, implementation, and benchmarking studies. Mount Pleasant, SC: Multisystemic Therapy Services. Retrieved from http:// mstservices.com/files/outcomestudies.pdf.

241. van der Stouwe, T., Asscher, J. J., Stams, G. J. J. M., Deković, M., van der Laan, P. H. (2014). The effectiveness of Multisystemic Therapy (MST): A meta-analysis. Clinical Psychology Review, 34(6), 468-481.

242. Sawyer, A. M., \& Borduin, C. M. (2011). Effects of Multisystemic Therapy through midlife: A 21.9-year follow-up to a randomized clinical trial with serious and violent juvenile offenders. Journal of Consulting and Clinical Psychology, 79(5), 643-652.

243. Wagner, D. V., Borduin, C. M., Sawyer, A. M., \& Dopp, A. R. (2014). Long-term prevention of criminality in siblings of serious and violent juvenile offenders: A 25-year follow-up to a randomized clinical trial of Multisystemic Therapy. Journal of Consulting and Clinical Psychology, 82(3), 492-499.

244. National Network of Hospital-based Violence Intervention Programs. (2016). NNHVIP: National Network of Hospital-based Violence Prevention Programs. Oakland, CA: National Network of Hospital-based Violence Intervention Programs. Retrieved from http://nnhvip.org/.

245. Becker, M. G., Hall, J. S., Ursic, C. M., Jain, S., \& Calhoun, D. (2004). Caught in the crossfire: The effects of a peer-based intervention program for violently injured youth. Journal of Adolescent Health, 34(3), 177-183.

246. Cunningham, R. M., Whiteside, L. K., Chermack, S. T., Zimmerman, M. A., Shope, J. T., Bingham, C. R., .. Walton, M. A. (2013). Dating violence: Outcomes following a brief motivational interviewing intervention among at-risk adolescents in an urban emergency department. Academic Emergency Medicine, 20(6), 562-569.

247. Zun, L. S., Downey, L., \& Rosen, J. (2006). The effectiveness of an ED-based violence prevention program. American Journal of Emergency Medicine, 24(1), 8-13.

248. Cunningham, R. M., Chermack, S. T., Zimmerman, M. A., Shope, J. T., Bingham, C. R., Blow, F. C., \& Walton, M. A. (2012). Brief motivational interviewing intervention for peer violence and alcohol use in teens: One-year follow-up. Pediatrics, 129(6), 1083-1090.

249. Walton, M. A., Chermack, S. T., Shope, J. T., Bingham, C. R., Zimmerman, M. A., Blow, F. C., \& Cunningham, R. M. (2010). Effects of a brief intervention for reducing violence and alcohol misuse among adolescents: A randomized controlled trial. Journal of the American Medical Association, 304(5), 527-535.

250. Carter, P. M., Walton, M. A., Zimmerman, M. A., Chermack, S. T., Roche, J. S., \& Cunningham, R. M. (2016). Efficacy of a universal brief intervention for violence among urban emergency department youth. Academic Emergency Medicine. http://doi. org/10.1111/acem.13021. 
251. Drake, E. (2012). Reducing crime and criminal justice costs: Washington state's evolving research approach. Justice Research and Policy, 14(1), 97-116.

252. Pew Charitable Trusts (2014). Evidence-based policymaking: A guide for effective government. Washington, DC: Pew Center on the States and MacArthur Foundation. Retrieved from http://www.pewtrusts.org/ /media/assets/2014/11/ evidencebasedpolicymakingaguideforeffectivegovernment.pdf?la=en.

253. Centers for Disease Control and Prevention (2016). The state health department's role in the policy process: A tool for state health department injury and violence prevention programs. Atlanta, GA: Centers for Disease Control and Prevention, National Center for Injury Prevention and Control. Retrieved from https://www.cdc.gov/injury/pdfs/shd_policy_tool-a.pdf.

254. Kania, J., \& Kramer, M. (2011). Collective impact. Stanford Social Innovation Review, Winter 2011, 36-41.

255. Kim, B. E., Gilman, A. B., \& Hawkins, J. D. (2015). School-and community-based preventive interventions during adolescence: Preventing delinquency through science-guided collective action. In J. Morizot, L. Kazemian (Eds.), The development of criminal and antisocial behavior (pp. 447-460). Switzerland: Springer International Publishing.

256. Centers for Disease Control and Prevention. (2016). National Violent Death Reporting System. Atlanta, GA: Centers for Disease Control and Prevention, National Center for Injury Prevention and Control. Retrieved from http://www.cdc.gov/ violenceprevention/nvdrs/index.html.

257. Brener, N. D., Kann, L., Shanklin, S., Kinchen, S., Eaton, D. K., Hawkins, J., \& Flint, K. H. (2013). Methodology of the Youth Risk Behavior Surveillance System-2013. Morbidity and Mortality Weekly Report, 62(RR-1), 1-23.

258. Bureau of Justice Statistics (2016). Bureau of Justice Statistics. Washington, DC: U.S. Department of Justice, Office of Justice Programs. Retrieved 2016 from http://www.bjs.gov.

259. Office of Juvenile Justice and Delinquency Prevention. (2016). Statistical briefing book. Washington, DC: U.S. Department of Justice, Office of Justice Programs, Office of Juvenile Justice and Delinquency Prevention. Retrieved from http://www.ojjdp. gov/ojstatbb/about.html.

260. Kingston, B., Macallao, M., Smokowski, P., Sullivan, T., \& Sutherland, K. (2016). Constructing "packages" of evidence-based programs to prevent youth violence: processes and illustrative examples from CDC's Youth Violence Prevention Centers. Journal of Primary Prevention, 37(2), 141-163. 


\section{Appendix: Summary of Strategies and Approaches to Prevent Youth Violence}

\begin{tabular}{|c|c|c|c|c|c|}
\hline \multirow[b]{2}{*}{ Strategy } & \multirow[b]{2}{*}{$\begin{array}{l}\text { Approach/Program, } \\
\text { Practice or Policy }\end{array}$} & \multicolumn{3}{|c|}{ Best Available Evidence } & \multirow[b]{2}{*}{ Lead Sectors ${ }^{1}$} \\
\hline & & $\begin{array}{c}\text { Youth } \\
\text { Violence } \\
\text { Perpetration }\end{array}$ & $\begin{array}{c}\text { Youth } \\
\text { Violence } \\
\text { Victimization }\end{array}$ & $\begin{array}{l}\text { Risk/Protective } \\
\text { Factors for } \\
\text { Youth Violence }\end{array}$ & \\
\hline \multirow{8}{*}{$\begin{array}{l}\text { Promote Family } \\
\text { Environments } \\
\text { that Support } \\
\text { Healthy } \\
\text { Development }\end{array}$} & \multicolumn{4}{|l|}{ Early childhood home visitation } & \multirow{2}{*}{$\begin{array}{l}\text { Public health } \\
\text { Health care } \\
\text { Social services }\end{array}$} \\
\hline & Nurse Family Partnership ${ }^{\circledast}$ & $\checkmark$ & & $\checkmark$ & \\
\hline & \multicolumn{4}{|c|}{ Parenting skill and family relationship programs } & \multirow{6}{*}{$\begin{array}{l}\text { Public health } \\
\text { Education }\end{array}$} \\
\hline & The Incredible Years ${ }^{\circledR}$ & $\checkmark$ & & $\checkmark$ & \\
\hline & $\begin{array}{l}\text { Parent Management Training- } \\
\text { Oregon Mode }{ }^{\mathrm{TM}}\end{array}$ & $\checkmark$ & & $\checkmark$ & \\
\hline & Strengthening Families 10-14 & $\checkmark$ & & $\checkmark$ & \\
\hline & Coping Power & $\checkmark$ & & $\checkmark$ & \\
\hline & Familias Unidas $^{\mathrm{TM}}$ & $\checkmark$ & & $\checkmark$ & \\
\hline \multirow{3}{*}{$\begin{array}{l}\text { Provide Quality } \\
\text { Education Early } \\
\text { in Life }\end{array}$} & \multicolumn{4}{|c|}{ Preschool enrichment with family engagement } & \multirow{3}{*}{$\begin{array}{l}\text { Public health } \\
\text { Social services } \\
\text { Education }\end{array}$} \\
\hline & Child Parent Centers & $\checkmark$ & & $\checkmark$ & \\
\hline & Early Head Start & $\checkmark$ & & $\checkmark$ & \\
\hline \multirow{5}{*}{$\begin{array}{l}\text { Strengthen } \\
\text { Youth's Skills }\end{array}$} & \multicolumn{4}{|l|}{ Universal school-based programs } & \multirow{5}{*}{$\begin{array}{l}\text { Public health } \\
\text { Education }\end{array}$} \\
\hline & Good Behavior Game & $\checkmark$ & & $\checkmark$ & \\
\hline & $\begin{array}{l}\text { Promoting Alternative THinking } \\
\text { Strategies }^{\circledR}\end{array}$ & $\checkmark$ & & $\checkmark$ & \\
\hline & Life Skills ${ }^{\circledast}$ Training & $\checkmark$ & & $\checkmark$ & \\
\hline & Steps to Respect & $\checkmark$ & $\checkmark$ & $\checkmark$ & \\
\hline \multirow{5}{*}{$\begin{array}{l}\text { Connect Youth to } \\
\text { Caring Adults and } \\
\text { Activities }\end{array}$} & \multicolumn{4}{|l|}{ Mentoring programs } & \multirow{2}{*}{$\begin{array}{l}\text { Community } \\
\text { organizations } \\
\text { Education } \\
\end{array}$} \\
\hline & $\begin{array}{l}\text { Big Brothers Big Sisters } \\
\text { of America }\end{array}$ & $\checkmark$ & & $\checkmark$ & \\
\hline & \multicolumn{4}{|l|}{ After-school programs } & \multirow{3}{*}{$\begin{array}{l}\text { Community } \\
\text { organizations } \\
\text { Education }\end{array}$} \\
\hline & $\begin{array}{l}\text { Los Angeles' Better Educated } \\
\text { Students for Tomorrow }\end{array}$ & $\checkmark$ & & $\checkmark$ & \\
\hline & After School Matters & & & $\checkmark$ & \\
\hline
\end{tabular}




\begin{tabular}{|c|c|c|c|c|c|}
\hline \multirow[b]{2}{*}{ Strategy } & \multirow[b]{2}{*}{$\begin{array}{l}\text { Approach/Program, } \\
\text { Practice or Policy }\end{array}$} & \multicolumn{3}{|c|}{ Best Available Evidence } & \multirow[b]{2}{*}{ Lead Sectors ${ }^{1}$} \\
\hline & & $\begin{array}{c}\text { Youth } \\
\text { Violence } \\
\text { Perpetration }\end{array}$ & $\begin{array}{c}\text { Youth } \\
\text { Violence } \\
\text { Victimization }\end{array}$ & $\begin{array}{l}\text { Risk/Protective } \\
\text { Factors for } \\
\text { Youth Violence }\end{array}$ & \\
\hline \multirow{9}{*}{$\begin{array}{l}\text { Create Protective } \\
\text { Community } \\
\text { Environments }\end{array}$} & \multicolumn{4}{|c|}{ Modify the physical and social environment } & \multirow{3}{*}{$\begin{array}{l}\text { Business } \\
\text { Government } \\
\text { (local, state) }\end{array}$} \\
\hline & Business Improvement Districts & $\checkmark$ & & $\checkmark$ & \\
\hline & $\begin{array}{l}\text { Crime Prevention through } \\
\text { Environmental Design }\end{array}$ & $\checkmark$ & $\checkmark$ & $\checkmark$ & \\
\hline & \multicolumn{4}{|c|}{ Reduce exposure to community-level risks } & \multirow{3}{*}{$\begin{array}{l}\text { Business } \\
\text { Housing } \\
\text { Government } \\
\text { (local, state) } \\
\end{array}$} \\
\hline & Tax credits & $\checkmark$ & & $\checkmark$ & \\
\hline & $\begin{array}{l}\text { Alcohol policies } \\
\text { (outlet density, pricing) }\end{array}$ & $\checkmark$ & $\checkmark$ & $\checkmark$ & \\
\hline & \multicolumn{4}{|c|}{ Street outreach and community norm change } & \multirow{3}{*}{$\begin{array}{l}\text { Public health } \\
\text { Community } \\
\text { organzations }\end{array}$} \\
\hline & Cure Violence & $\checkmark$ & $\checkmark$ & $\checkmark$ & \\
\hline & Safe Streets & $\checkmark$ & $\checkmark$ & $\checkmark$ & \\
\hline \multirow{10}{*}{$\begin{array}{l}\text { Intervene to } \\
\text { Lessen Harms } \\
\text { and Prevent } \\
\text { Future Risk }\end{array}$} & \multicolumn{4}{|c|}{ Treatment to lessen the harms of violence exposures } & \multirow{3}{*}{$\begin{array}{l}\text { Health care } \\
\text { Social services } \\
\text { Community } \\
\text { organizations }\end{array}$} \\
\hline & $\begin{array}{l}\text { Trauma-Focused Cognitive } \\
\text { Behavioral Therapy }\end{array}$ & $\mathrm{N} / \mathrm{A}^{2}$ & $\mathrm{~N} / \mathrm{A}^{2}$ & $\checkmark$ & \\
\hline & $\begin{array}{l}\text { Cognitive Behavioral Intervention } \\
\text { for Trauma in Schools }\end{array}$ & $N / A^{2}$ & $\mathrm{~N} / \mathrm{A}^{2}$ & $\checkmark$ & \\
\hline & \multicolumn{4}{|c|}{ Treatment to prevent problem behavior and future involvement in violence } & \multirow{4}{*}{$\begin{array}{l}\text { Health care } \\
\text { Social services } \\
\text { Justice }\end{array}$} \\
\hline & Functional Family Therapy & $\checkmark$ & & $\checkmark$ & \\
\hline & $\begin{array}{l}\text { Multidimensional Treatment } \\
\text { Foster Care }\end{array}$ & $\checkmark$ & & $\checkmark$ & \\
\hline & Multisystemic Therapy ${ }^{\circledast}$ & $\checkmark$ & & $\checkmark$ & \\
\hline & \multicolumn{4}{|l|}{ Hospital-community partnerships } & \multirow{3}{*}{$\begin{array}{l}\text { Health care } \\
\text { Community } \\
\text { organizations }\end{array}$} \\
\hline & SafERteens & $\checkmark$ & $\checkmark$ & $\checkmark$ & \\
\hline & Caught in the Crossfire & $\checkmark$ & & $\checkmark$ & \\
\hline
\end{tabular}

'This column refers to the lead sectors well positioned to bring leadership and resources to implementation efforts. For each strategy, there are many other sectors, such as non-governmental organizations, that are instrumental to prevention planning and implementing the specific programmatic activities.

${ }^{2}$ The program is designed to lessen the harms of violence exposures (e.g., post-traumatic stress disorder, depression, behavioral problems) 


\section{For more information}

To learn more about preventing youth violence, call 1-800-CDC-INFO or visit CDC's violence prevention pages at www.cdc.gov/violenceprevention. 